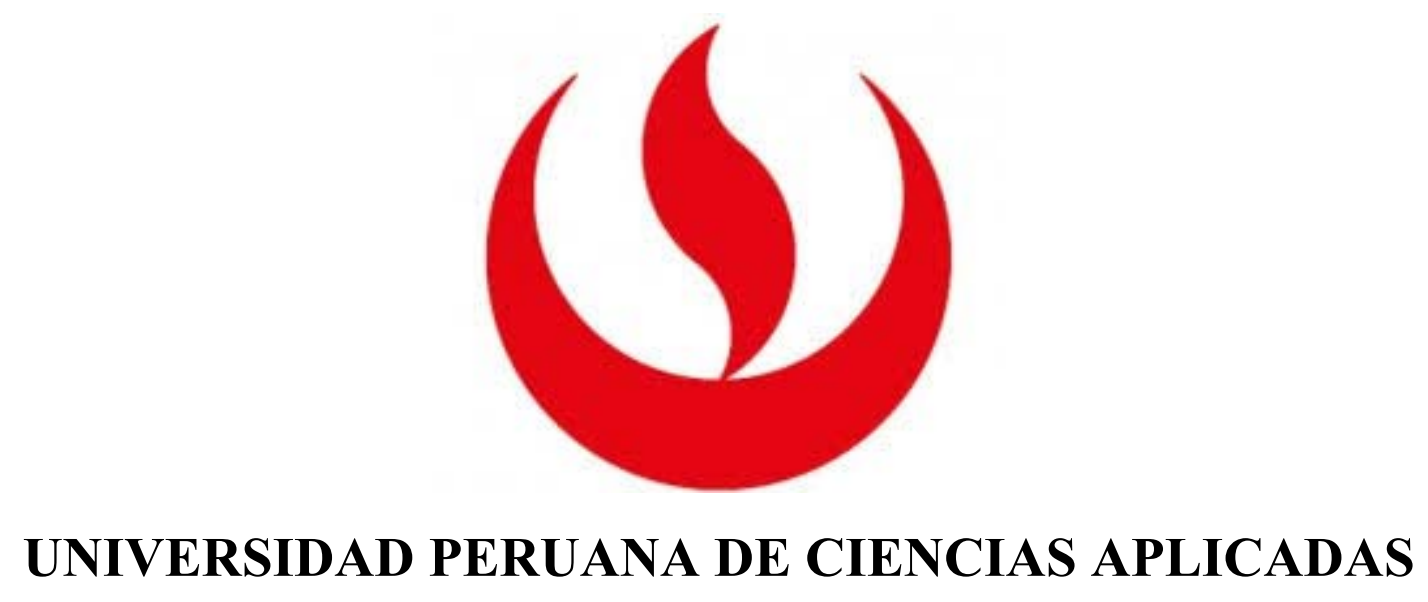

Facultad de Psicología

Carrera de Psicología

\title{
Burnout y Calidad de Vida Profesional en Policías de Lima Metropolitana
}

\section{TESIS}

Para optar el título profesional de Licenciado en Psicología

\section{AUTOR}

Ana Lucia Zuazo Uribe (0000-0003-3234-3801)

\section{ASESOR DE TESIS}

Eduardo Luis Manzanares Medina (0000-0002-3377-311X) 
La presente investigación está dedicada a mi padre que con su amor, confianza y apoyo incondicional, me impulsó a culminar esta etapa de formación profesional. Asimismo, a mi madre que con su cariño, ejemplo de persistencia y voluntad me inculcó las enseñanzas para esforzarme a cumplir este logro académico con éxito. 


\section{Resumen}

El objetivo del presente estudio fue conocer la relación entre el Síndrome de Burnout y la Calidad de Vida Profesional en Policías de Lima Metropolitana. Para ello, se realizó un estudio de tipo correlacional y de diseño transversal en una muestra conformada por 200 efectivos policiales, de los cuales el 27.5\% (55) son mujeres y el 72.5\% (145) hombres, con edades entre los 19 y 60 años $(M=35.87)$. Los instrumentos utilizados fueron el Inventario de Burnout de Maslach y el Inventario de Calidad de Vida Profesional (CVP). Los resultados mostraron una correlación negativa y significativa entre la dimensión distanciamiento emocional con el apoyo directivo $\left(r_{s}=-.43 ; p<.001\right)$ y motivación intrínseca $\left(r_{s}=-.35 ; p\right.$ $<.001)$; por el contrario, una relación positiva y significativa con la carga de trabajo $\left(r_{s}=.59\right.$; $p<.001)$. Adicionalmente, se encontró una correlación positiva y significativa entre la dimensión realización personal con el apoyo directivo $\left(r_{s}=.35 ; p<.001\right)$ y motivación intrínseca $\left(r_{s}=.44 ; p<.001\right) ; \mathrm{y}$ de forma opuesta una correlación negativa y significativa con la carga de trabajo $\left(r_{s}=-.14 ; p<.05\right)$.

Palabras Clave: Síndrome de Burnout, Distanciamiento Emocional, Realización Personal, Calidad de Vida Profesional, Motivación Intrínseca. 


\begin{abstract}
The objective of the present study was to find out the relationship between Occupational Burnout and the Professional Life Quality of Police Officers in Metropolitan Lima. To accomplish this, a cross-sectional correlational study was carried out in a sample made up of 200 policemen from the Emergency Unit, from which $27.5 \%$ (55) are women and $72.5 \%$ (145) men, with ages between 19 and 60 years old $(M=35.87)$. The instruments used were the Maslach Burnout Inventory and the Professional Life Quality Inventory. The results showed a significant negative correlation between the emotional distancing dimension with direct support $\left(r_{s}=-.43 ; p<.001\right)$ and intrinsic motivation $\left(r_{s}=-.35 ; p<.001\right)$; on the other hand, a significant positive relationship with the workload $\left(r_{s}=.59 ; p<.001\right)$. Additionally, a significant positive correlation was found between the dimension of personal fulfillment with direct support $\left(r_{s}=.35 ; p<.001\right)$ and intrinsic motivation $\left(r_{s}=.44 ; p<.001\right)$; and in the opposite way a significant negative correlation with the workload $\left(r_{s}=-.14 ; p<.05\right)$.
\end{abstract}

Keywords: Occupational Burnout, Emotional Distancing, Personal Fulfillment, Professional Life Quality, Intrinsic Motivation. 


\section{Tabla de Contenidos}

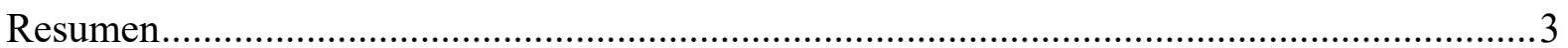

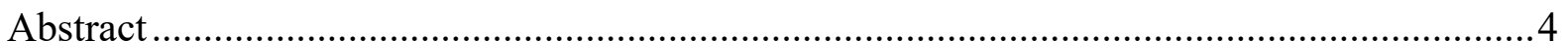

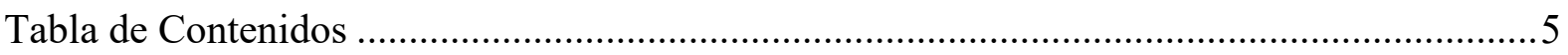

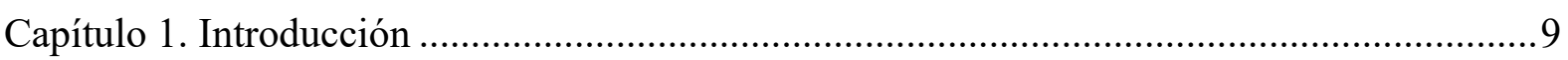

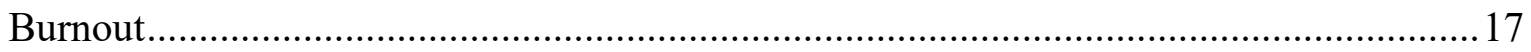

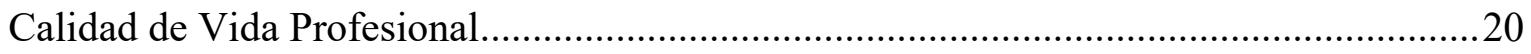

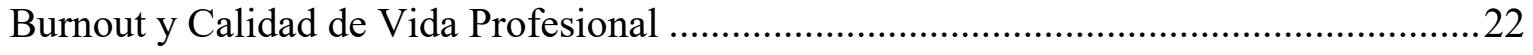

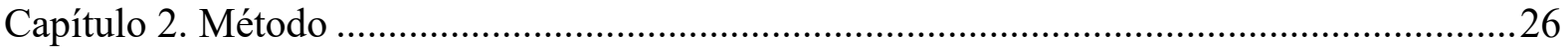

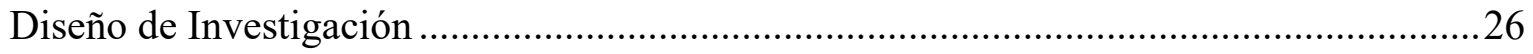

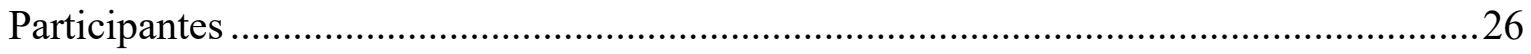

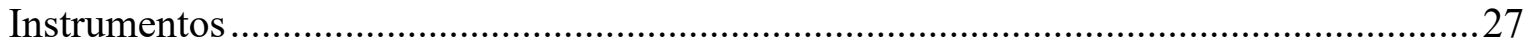

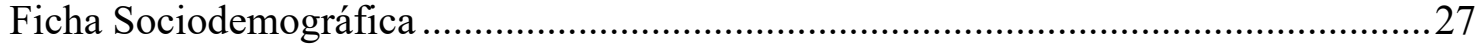

Inventario de Burnout de Maslach (Maslach \& Jackson, 1981) ..................................28

Escala de Calidad de Vida Profesional (CVP - 35) (Cabezas, 1998) ..............................30

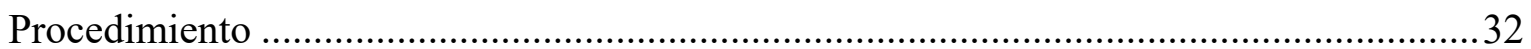

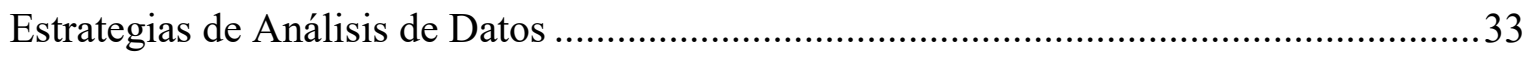

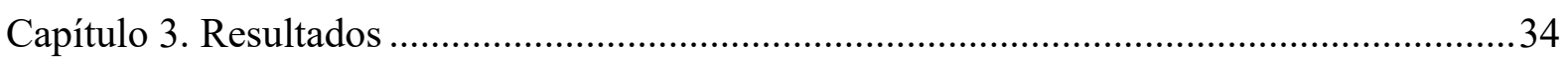

Evidencias de Validez y Confiabilidad de los Instrumentos................................................. 34

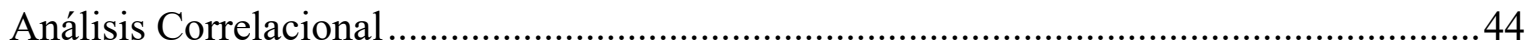

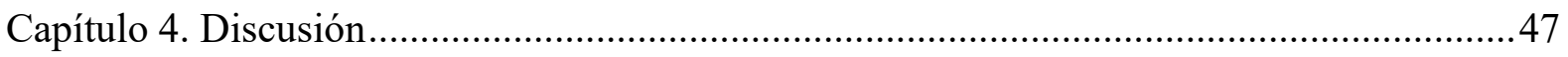

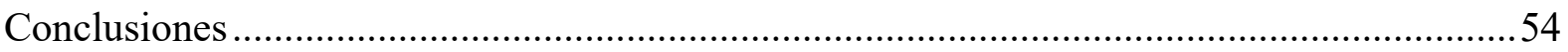

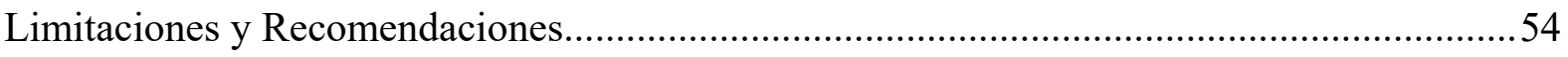

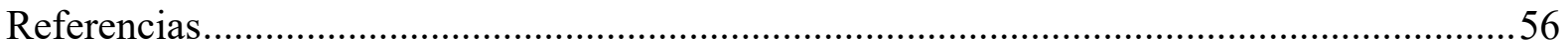

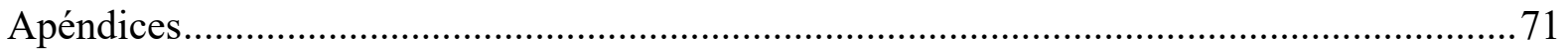

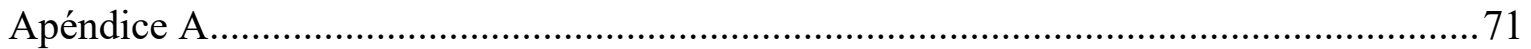




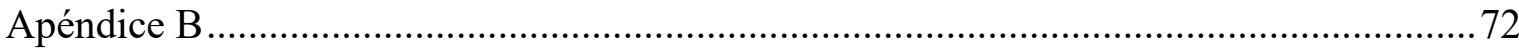

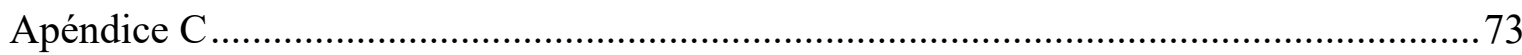

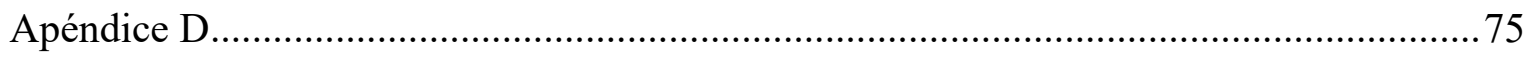

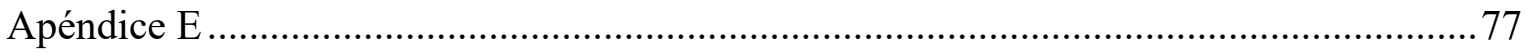




\section{Índice de Tablas}

Tabla 1 .37

Cargas factoriales del análisis factorial exploratorio del Inventario de Burnout de Maslach .37

Tabla 2 .

Cargas factoriales del análisis factorial exploratorio de la Escala de Calidad de Vida Profesional.

Tabla 3.

Estadísticos descriptivos de la variable Síndrome de Burnout y Calidad de Vida Profesional

Tabla 4

Prueba de Normalidad de las Variables Síndrome de Burnout y Calidad de Vida Profesional .44

Tabla 5 . ... .46

Matriz de correlación de las variables Síndrome de Burnout y Calidad de Vida Profesional y Variables Sociodemográficas. 46 


\section{Índice de Figuras}

Figura 1. Gráfico de sedimentación de Cattel del MBI...............................35

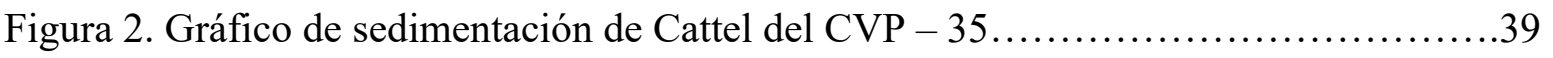




\section{Capítulo 1. Introducción}

Una de las enfermedades relacionadas con el estrés laboral es el síndrome de burnout (Castañeda \& García, 2010), que afecta la motivación emocional y cognitiva del profesional originando el desinterés por su trabajo (Gantiva, Tabares \& Villa, 2010), deteriorando su calidad de vida profesional, al condicionar su productividad, bienestar laboral y sentido de pertenencia en su entorno de trabajo (Rodríguez \& Chávez, 2018). Los profesionales que atraviesan con mayor frecuencia por esta situación, son los dedicados a prestar cuidado y protección a las personas (personal sanitario, educadores, trabajadores sociales y personal de las fuerzas armadas) (López, Osca \& Rodríguez, 2008). En tal sentido, el trabajo policial es una profesión que implica una continua exposición a situaciones de estrés y peligro, que ponen en riesgo la salud del colaborador y su desempeño (Valladares, 2017).

La Policía Nacional del Perú es una institución, que tiene como objetivo: “mantener y restablecer el orden interno; prevenir, investigar y combatir los delitos y faltas; prestar protección y ayuda a las personas, y a la comunidad; garantizar el cumplimiento de las leyes y la seguridad del patrimonio público y privado" (Decreto Legislativo $N^{\circ} 1148,2012$, p. 1). Dentro de la Policía Nacional del Perú, tienen como principales funciones: controlar y enfrentar la delincuencia, así como proteger la integridad física y bienes de los ciudadanos. Asimismo, interceder frente a situaciones de alto riesgo, prestando primos auxilios, rescatando y brindando seguridad a la población en casos de siniestros y desastres (Decreto Supremo $\left.\mathrm{N}^{\circ} 026,2017\right)$.

Para desempeñar estas funciones con eficacia y eficiencia es necesario que se evalué durante el proceso de selección que el policía cuente con un determinado perfil de competencias tales como: compromiso de la democracia y derechos humanos, sólida formación ética y moral, aptitudes sociales, capacidad del trabajo en equipo y análisis, entre 
otros; para que sea un candidato idóneo capaz de servir de manera adecuada las necesidades de la población, ayudando a la mejora integral de la institución (Arriola, Bocanegra \& Sim, 2017). Sin embargo, como sostiene Villanueva (como se citó en Arriola et al., 2017) el proceso de reclutamiento y selección de la policía nacional no es el adecuado, debido a que presenta diversas limitaciones como: la falta de lineamientos y perfiles estandarizados que garanticen el adecuado desenvolvimiento de sus funciones.

Asimismo, es necesario que la formación policial integre capacidades de resolución de problemas (García, 2015), que permitan afrontar el estrés al que son vulnerables, debido a que en los últimos años han ocurrido manifestaciones de violencia que han generado la desaprobación de la población, afectando la imagen institucional (Decreto Supremo Nº 0262017-IN, 2017). Por lo cual, actualmente la formación policial, procura "la idoneidad y eficacia de la Policía Nacional del Perú para el cumplimiento de sus funciones, garantizando así la prestación de un servicio y derecho fundamental para la sociedad" (Decreto Legislativo $\mathrm{N}^{\circ} 1318,2017$, p. 2).

El rol profesional del efectivo policial está relacionado con riesgos ocupacionales que afectan su bienestar psicológico y reduce su capacidad de trabajo, interfiriendo en su desempeño de velar por la seguridad pública y en el adecuado funcionamiento de la institución policial (Basinska, Wiciak \& Dåderman, 2014). Por ello, es necesario fortalecer la profesionalización de la Policía Nacional, acorde con las necesidades reales de su labor, asignándole prioridad al factor humano como un pilar fundamental de progreso, dotándolo de mejores capacidades y conocimientos, acorde con las demandas actuales de la sociedad que permitan a la policía brindar un servicio de calidad (Castillo, 2015). 
La profesión policial es una ocupación inherentemente estresante, debido a que está directamente relacionada con el estrés y otros factores de carácter organizativo tales como: jornadas de trabajo extensas, disponibilidad de horarios, trabajos rotativos, permanente evaluación del desempeño, tener varios jefes con distintas políticas, la falta de reconocimiento de su esfuerzo por parte de la comunidad y la exposición continua de su vida (Corredor \& Marín, 2013; Sánchez, Sanz, Apellániz \& Pascual, 2001). Asimismo, existen algunos factores críticos estresantes propios de la labor policial que generan el síndrome de burnout, entre ellos: el inadecuado liderazgo, los conflictos de roles, la exposición a la violencia y las presiones del tiempo para el cumplimiento de su tarea (Vuorensyrjä \& Mälkiä, 2011).

En el Perú las características del perfil profesional del efectivo policial, exige una rigurosa preparación y actitud, debido a que está constantemente expuesto a situaciones de emergencia, lo cual requiere de profesionales dotados de un razonamiento adecuado y estabilidad emocional, para desempeñarse con eficiencia y eficacia al enfrentar las demandas de los ciudadanos durante sus intervenciones policiales. Esta respuesta se puede ver afectada por factores personales (inteligencia emocional, control de la ira y comunicación asertiva), familiares (violencia familiar), laborales (dificultad para adaptarse al servicio policial, dificultades disciplinarias y gestión del estrés) y económicos (remuneración) que originan altos niveles de estrés y conductas disfuncionales, tales como: conductas violentas y conductas ilícitas o faltas que son originadas por las carencias del proceso de selección (valores e identidad Institucional) (Resolución Directoral N²00-2018-DIRGEN/IGPNP,2018).

En este sentido, se requiere por parte de la organización policial orientar sus esfuerzos y recursos organizacionales hacia la creación de servicios que manejen efectivamente los problemas de salud y de carácter personal relacionados con el trabajo policial (Durán \& 
Montalbán, 2000). Asimismo, es necesario que el personal directivo de la institución limite el impacto de los riesgos psicosociales, aplicando programas de gestión para prevenir y reducir las consecuencias crónicas del síndrome de burnout (Basinska \& Wiciak, 2012).

En el contexto peruano, las investigaciones sugieren que las características propias de la labor policial, las condiciones de trabajo y el contexto organizativo en el que los policías desarrollan sus labores, los vuelve vulnerables frente a la posibilidad de padecer del síndrome de burnout en respuesta al estrés laboral crónico (Romero, 2015).

Los estudios descriptivos realizados en policías analizaron la relación entre el síndrome de burnout y las variables sociodemográficas. En la investigación realizada por Cabanillas (2016), se analizó una muestra de 274 policías de la Unidad de Control de Transito de Lima Centro, en la cual se encontró una relación significativa entre el síndrome de burnout y la edad y el tiempo de servicio. Sin embargo, no se encontraron diferencias significativas entre el sexo, estado civil y número de hijos.

En otro estudio elaborado por Callirgos (2017), se examinó una muestra compuesta por 261 suboficiales de las comisarias del Cercado de Lima, en la que se encontró que existe una relación significativa entre el tiempo de servicio y el síndrome de burnout. No obstante, no se encontró una relación significativa entre el síndrome de burnout y las funciones desempeñadas por los suboficiales y edad.

Por otro lado, Valladares (2017), elaboró un estudio de prevalencia del síndrome de burnout en una muestra de 64 agentes policiales, en la que se obtuvo como resultado que el $56.3 \%$ de los agentes policiales presenta un nivel intermedio de síndrome de burnout, el 23.4\% un nivel bajo y el 20.3\% un nivel alto. A partir de ello, se concluyó que más del 70\% de los agentes policiales están expuestos a los riesgos del burnout. 
Asimismo, se realizaron estudios del síndrome de burnout en otras profesiones de servicio público (personal de salud y profesores). En el estudio de prevalencia del síndrome de burnout realizado por Toledo (2016), se encontró que el $44.6 \%$ del personal de salud de la Clínica Maison de Sante obtuvo un agotamiento emocional elevado, mientras que el 76.7\% presentó elevada despersonalización y el $60.7 \%$ un nivel bajo de realización personal. De igual manera, Arias y Jiménez (2012), realizaron una investigación sobre la incidencia del síndrome de burnout en 233 profesores de educación básica en la ciudad de Arequipa en donde se encontró que el 93.7\% del personal masculino presentan un nivel medio de burnout, mientras que el 91.5\% del personal femenino presentó un nivel intermedio. Ambos estudios, no profundizan en el análisis de la variable, por lo tanto, son de carácter descriptivo, por lo que dan a conocer las características de la condición del burnout en esas poblaciones.

A nivel de análisis de la variable, se realizaron estudios de tipo correlacional en personal policial. Uno de ellos examino la relación entre la inteligencia emocional y el síndrome de burnout en 130 suboficiales de la ciudad de Arequipa. El resultado del estudio evidencio que existe una relación inversa y significativa entre la inteligencia emocional y el síndrome de burnout (Calienes \& Díaz, 2012).

En otra investigación, se examinó la relación entre síndrome de burnout y agresividad en una muestra de 236 efectivos policiales de la ciudad de Lima. El resultado demostró que existe una correlación significativa y positiva entre el síndrome de burnout y la agresividad en los efectivos de la comisaría del distrito de Comas (Gonzales, 2017).

De manera similar, en un estudio que evaluó la relación entre el síndrome de burnout y la satisfacción laboral en una muestra de 107 policías de la División de Operaciones Especiales, se encontró una relación negativa y significativa entre el burnout y la satisfacción laboral (Zárate, 2017). 
En otro estudio se analizó la relación entre el clima laboral y el síndrome de burnout en 187 trabajadores de la policía de la división de investigación e inspección. Los resultados mostraron que no existe una correlación significativa entre ambas variables (García, 2016).

Con respecto al análisis de correlación entre dimensiones de las variables afrontamiento y síndrome de burnout elaborado por Linares y Poma (2016), en una muestra de policías, se encontró que el afrontamiento enfocado en el problema tiene una relación inversa y significativa con la realización personal. Sin embargo, es positiva con la despersonalización. Asimismo, la relación con el agotamiento emocional fue positiva pero no significativa. Con respecto, al estilo de afrontamiento enfocado en la emoción se encontró una relación positiva y no significativa con el agotamiento emocional y la despersonalización. No obstante, fue negativa y no significativa con la realización personal.

Por otro lado, en personal de salud se analizó la relación entre el síndrome de burnout y el clima laboral en 30 profesionales del personal de asistencia de un Hospital Público de Lima. El resultado del estudio señaló una relación inversa significativa entre clima laboral y Burnout (Vizcarra, Llaja, Limo \& Talavera, 2015).

En otro estudio, sobre la prevalencia del síndrome de burnout y su relación con la existencia de factores de riesgo psicosociales en trabajadores de diferentes profesiones de la ciudad de Lima, se encontró que el síndrome de burnout se encuentra relacionado con la existencia de factores de riesgo psicosociales como: "exigencias laborales, la carga de trabajo, el contenido y características de la tarea y las condiciones del lugar de trabajo" (López, García \& Pando, 2014, p. 168); y se determinó que las exigencias laborales originan el síndrome de burnout, debido a que promueven la despersonalización del colaborador, y una mayor carga de trabajo afecta su realización personal (López et al., 2014). 
En el contexto internacional Xavier y Prabhakar (2016), realizaron un estudio en el personal policial, en donde se encontró que los factores de nivel administrativo y organizacional repercuten en el desarrollo del síndrome de burnout. Asimismo, en la investigación de McCarty y Skogan (2012), realizada en 12 agencias policiales se obtuvo como resultado que las dificultades y responsabilidades de la labor policial influyen en la aparición del burnout. Sin embargo, a nivel nacional solo se encontró la investigación de Romero (2015), sobre el síndrome de burnout aplicada al personal policial, por lo que su estudio amerita ser abordado.

La aparición del síndrome de burnout en los efectivos policiales se origina por las características de los servicios que ofrecen y de su entorno institucional. Con respecto al servicio la relación frecuente y directa que los policiales mantienen con personas que se encuentran en situaciones de riesgo y sufrimiento (Briones, 2007), desencadenan agotamiento emocional. Por otro lado, con respecto al contexto organizativo, la excesiva carga laboral, la errónea distribución de las funciones laborales y la ineficiente asignación de los tiempos de ejecución de sus funciones (Sánchez et al., 2001), incrementa la despersonalización del personal policial. De manera similar, la falta de oportunidades de crecimiento profesional, la inestabilidad laboral, la inequidad entre la remuneración y la jerarquía del cargo (Sánchez et al., 2001); así como el inadecuado reconocimiento y recompensa financiera e institucional, incrementa la vulnerabilidad del colaborador de padecer el síndrome de burnout debido al deterioro de la calidad de su trabajo y de sí mismo, lo cual disminuye su realización personal (Maslach \& Leiter, 2016b).

Por tal motivo, esta investigación se centra principalmente en investigar la relación del síndrome de burnout y calidad de vida profesional en los miembros de la Policía Nacional del Perú, debido a que por las características de su rol laboral se encuentran expuestos a desarrollar el síndrome de burnout. En este sentido, la sobrecarga laboral, las expectativas y 
el esfuerzo implicados en el desarrollo de las funciones, originan estrés laboral crónico en los profesionales que se encuentran en constante relación con la comunidad, por lo que el clima laboral que perciben en la organización, se manifiesta proporcionalmente en el servicio que ofrecen a las personas (Álvarez, Sánchez \& Lorenzo, 2006).

De acuerdo a lo expuesto anteriormente, se considera relevante teóricamente realizar esta investigación debido a que es el primer estudio en el Perú que analiza la interacción de las dos variables en el personal de la policía. Por lo tanto, será de utilidad al poner de manifiesto que los componentes del burnout (distanciamiento emocional y despersonalización) originados por el estrés laboral, impactan significativamente en los factores que integran la calidad de vida profesional (motivación intrínseca, apoyo directivo y carga de trabajo), reduciendo su bienestar y satisfacción laboral, lo que puede afectar su desempeño y productividad. Lo cual, debería ser considerado por la institución debido a que el burnout es un síndrome que afecta la salud mental del policía deteriorando sus interacciones y el servicio que ofrece a la comunidad de manera eficiente y eficaz. Estos hallazgos servirán para brindar nuevos conocimientos que aporten a futuras investigaciones sobre el tema. Asimismo, es de alcance metodológico porque propone la aplicación de dos instrumentos para analizar de qué manera se presenta la relación entre el síndrome de burnout y la calidad de vida profesional en la profesión policial. La cual puede servir como referencia para otras investigaciones que examinen a profesionales expuestos a situaciones de riesgo y violencia tales como: las fuerzas armadas, bomberos, entre otros. Además, es de alcance social porque plantea la prevención del burnout como una estrategia para preservar la calidad de vida profesional garantizando la consecución de los objetivos de la organización, que será de utilidad para los profesionales del ámbito organizacional y de la salud. Por lo tanto, como señala Maslach (2009), el estudio del síndrome de burnout permite a las organizaciones reconocer los rasgos que caracterizan al individuo propenso al burnout y las condiciones del 
entorno de la organización para diseñar intervenciones que reduzcan el mismo. En este sentido, se espera que a partir de los resultados obtenidos la Policía Nacional del Perú reconozca la importancia del burnout y reformule sus estrategias organizacionales para garantizar la calidad de vida profesional y brindar un servicio de calidad a la sociedad, integrando a futuro en su programa de salud emocional preventivo la evaluación del burnout y calidad de vida profesional a todo el personal que se encuentre en actividad.

Es pertinente, desde el punto de vista práctico, porque los resultados proporcionarán al personal de salud mental del Hospital de la Policía Nacional del Perú la evidencia para desarrollar las intervenciones dirigidas a prevenir el síndrome de burnout en el personal policial. Una vez considerados los factores de riesgos psicosociales y organizacionales que influyen en el comportamiento y afectan el desempeño laboral del policía, será posible preservar su bienestar y motivación laboral. A su vez, permitirá que brinden una atención adecuada a la población (Jorge, Blanco, Issa, Romero \& Gayoso, 2005).

\section{Burnout}

El burnout es una respuesta emocional e interpersonal crónica y prolongada a los estresores del ambiente laboral; y se define por un modelo de tres componentes, cuya importancia sitúa la experiencia del estrés individual en un contexto social en el que se incluyen la percepción de la persona de sí mismo y de los demás (Maslach \& Leiter, 2016a). Los componentes de este modelo son: agotamiento emocional (es el componente individual del burnout, que hace referencia a sentirse sobre exigido y carente de recursos emocionales y físicos), baja realización personal (se refiere a los sentimientos que tiene el individuo de sentirse incompetente y carente de logros, las dudas del lugar que ocupa en el trabajo y la disminución de la productividad) y despersonalización (el factor interpersonal del burnout que se manifiesta en respuesta del agotamiento emocional, con actitudes negativas frente a 
los demás, irritabilidad y evasión, como una forma de autoprotección) (Maslach, 2015; Maslach \& Leiter, 2016b; Maslach, Schaufeli \& Leiter, 2001).

En el Perú, Romero (2015) encontró que gran parte de los efectivos policiales destinaban sus días libres para realizar diversas actividades, dedicándose principalmente a trabajar fuera de la institución policial, causando sentimientos de agotamiento, atribuido principalmente al exceso de trabajo y al desempeño de dos empleos. Asimismo, se reconoció que su labor no era valorada y debidamente recompensada en términos económicos. Además de ello, por las dificultades burocráticas que presentaba la organización, los policías perdieron la motivación inicial que tuvieron al momento de postular a la institución.

En el estudio comparativo de Arias y Jiménez (2012), realizado en enfermeras, policías y docentes de Arequipa, se encontró que los policías son los profesionales con mayor presencia del síndrome de burnout, al presentar mayores niveles de baja realización profesional, seguida por la despersonalización y por último el agotamiento emocional.

Los resultados de las investigaciones señalan que el burnout "es un importante factor de riesgo para la salud mental, y esto puede tener un impacto significativo tanto en la vida familiar como en la vida laboral del empleado afectado" (Maslach, 2009, p. 39).

En consecuencia es indispensable que las organizaciones identifiquen y evalúen frecuentemente los factores que promueven y deterioran el bienestar de los profesionales (Patlán, 2013), ya que el burnout representa un riesgo ocupacional, principalmente para las profesiones orientadas a proporcionar servicios humanos, médicos y de educación, en los cuales los entornos de trabajo exigen altas demandas y brindan bajos recursos, debido a que la interacción continua y directa del colaborador con las personas de su entorno laboral pueden ser estresante por el contacto personal y emocional, al priorizar las necesidades de los demás frente a las suyas (Maslach \& Leiter, 2016b). Por ello, es fundamental implementar 
intervenciones que permitan atender a los trabajadores con la finalidad de evitar las consecuencias en la salud ocupacional y mantener la satisfacción.

En la actualidad, las organizaciones se encuentran interesadas en monitorear los factores psicosociales ocupacionales que originan deficientes condiciones de trabajo y promueven la aparición del síndrome de burnout tales como: ausentismo, accidentes de trabajo, ineficiente desempeño del trabajo y baja productividad; con la finalidad de prevenir el burnout e incrementar el compromiso del colaborador para mejorar su desempeño (Schaufeli, 2017). Por lo tanto, para minimizar las deficiencias en el rendimiento del colaborador y de la organización se han propuesto intervenciones dirigidas tanto a prevenir el síndrome burnout, como a tratarlo una vez manifestado. Estas intervenciones se han enfatizado generalmente en estrategias individuales (estrategias de afrontamiento, relajación, mejora de la calidad de vida), en lugar de proponer estrategias de carácter organizativo y social (equilibrio en la carga de trabajo, apoyo de los colegas, líderes y familiares) (Maslach \& Leiter, 2016b).

Por ello, las organizaciones están innovando las políticas de calidad de vida profesional como una forma de optimizar el desempeño de la organización y retener a los mejores talentos. Las organizaciones competitivas en su búsqueda por la calidad y eficiencia, prestan importancia al rol que desempeña el trabajador, por lo que la calidad de vida profesional es importante para el éxito de toda organización. 


\section{Calidad de Vida Profesional}

La calidad de vida profesional se define como la satisfacción que percibe el colaborador entre las exigencias y las facultades psicológicas, organizacionales y relacionales de las que dispone para afrontarlas (García-Sánchez como se citó en Alonso, Iglesias \& Franco, 2002).

La calidad de vida profesional se encuentra influida por elementos personales (edad, sexo, personalidad), familiares (estado civil, apoyo familiar) y profesionales (oportunidades de crecimiento profesional), que condicionan el ambiente organizacional. Estos elementos pueden ser transformados mediante cambios realizados en la organización asociados con una adecuada gestión del reconocimiento, las condiciones laborales, la eficiente dirección (Alonso et al., 2002), y la adecuada gestión de las demandas de carga de trabajo que constituyen una estrategia vital de recuperación del equilibro para prevenir el agotamiento emocional del colaborador en la organización (Maslach \& Leiter, 2016b).

En este sentido como sostienen Muñoz, Coll, Torrent y Linares (2004) el clima organizacional repercute en la calidad de vida profesional, principalmente en la motivación y el apoyo laboral que los colaboradores experimentan con respecto al ambiente de trabajo. Por ello, para promover la eficiencia en la organización, e incrementar el rendimiento y satisfacción de los colaboradores es importante preservar la calidad de vida profesional, ya que, como afirman Rivera, Rivera y González (2016), la calidad de vida profesional incide en el desenvolvimiento psicológico y socioprofesional del colaborador, incentivando la creatividad y adaptación frente a los cambios en la organización.

Por lo cual, las organizaciones deben implementar estrategias para favorecer los elementos que promueven la calidad de vida profesional, otorgando mayor empoderamiento en la toma de decisiones a los colaboradores y tiempos de descanso durante la jornada 
laboral (Faleiros, 2008), ya que cuando los colaboradores se encuentran expuestos al estrés psicológico de las personas de su entorno laboral presentan una mayor carga emocional, que puede deteriorar su calidad de vida profesional y su capacidad para brindar un mejor servicio a la sociedad (Somoray, Shakespeare-Finch \& Armstrong, 2017).

En este sentido, Villarín, Méndez, Zuzúarregui, Sánchez y Conejo (2015) para conocer la calidad de vida profesional de los médicos de atención primaria del área sanitaria de Toledo, elaboraron un estudio en el cual encontraron que la percepción de apoyo directivo reflejó un valor mínimo y la carga de trabajo un valor intermedio, lo cual se asocia con un deterioro de la calidad de vida profesional total. No obstante, la motivación intrínseca fue alta. Por lo que, los autores sugieren que estos médicos muestran un gran compromiso en su labor profesional.

Asimismo, en el estudio realizado por López, López, Jareño y Moya (2008), para determinar la relación entre los tipos de gestión y la calidad de vida profesional de enfermeros de una residencia de mayores, se concluyó que la motivación profesional era media baja, por lo que es indispensable un cambio cultural que permita la participación y motivación de los colaboradores, y promueva el apoyo directivo.

Por otro lado, en la investigación realizada por Macías, Gutiérrez, Carmina y Crespillo (2014), se encontró que existe relación significativa entre la calidad de vida profesional, la inteligencia emocional percibida y el grado de cumplimiento de los objetivos organizacionales. Por lo que, los autores sugieren que la gestión de la organización debe estar dirigida a incentivar el desarrollo de las habilidades de la inteligencia emocional que proporcionen al colaborador contar con las herramientas necesarias para afrontar las situaciones de limitación y constante presión que atraviesan en su lugar de trabajo. 


\section{Burnout y Calidad de Vida Profesional}

La adecuada gestión de la calidad de vida profesional en las organizaciones es importante, porque previene los riesgos asociados con el desgaste profesional (García, Gálvez \& Rodríguez, 2009). En consecuencia para prevenir el síndrome de burnout en los efectivos policiales, se requiere que la institución realice una modificación dirigida a fortalecer las capacidades de su personal y optimizar los recursos de la organización, de tal forma que los trabajadores puedan dirigir su "potencial productivo" acorde a las exigencias desfavorables que se puedan presentar en el ambiente de trabajo (Durán, 2010).

En tal sentido, el trabajo policial se caracteriza por el elevado nivel de exigencias que incrementa la tensión y afecta la salud psicológica y las interacciones que mantienen dentro de la institución (Prashant, 2014). Por tal motivo, para optimizar el rendimiento de los efectivos policiales es necesario realizar intervenciones para mejorar su bienestar (Easton, Van Laar \& Marlow-Vardy, 2013), ya que como resaltan García et al. (2009) la satisfacción y el bienestar de los colaboradores se asocian al síndrome de burnout y la calidad de vida profesional, y como ambos constructos miden componentes diferentes que se encuentran fuertemente vinculados, identifican factores importantes de la gestión del talento humano, que pueden mejorar calidad de vida profesional, y por ende la calidad del servicio que ofrecen a la sociedad.

Por lo cual, para las organizaciones debería ser de interés conservar la calidad de vida profesional de sus colaboradores, debido a que el síndrome de burnout es un problema generado por el ambiente social y no por la persona (Maslach, 2009), atribuido principalmente al entorno laboral, en el cual los colaboradores experimentan una amplia gama de exigencias emocionales, físicas y psicológicas (Maslach \& Leiter, 2016a). En consecuencia, cuando la organización no valora la parte humana del trabajo y se encuentran 
desequilibrios entre las condiciones de la persona y el ambiente de trabajo existe un mayor riesgo de burnout, lo que origina un menor rendimiento, problemas familiares y deterioro de la salud (Maslach, 2009).

En tal sentido, Gonzáles y Sandoval (2016), analizaron la relación entre el síndrome de burnout y calidad de vida profesional en una muestra de 161 enfermeras del Hospital María Auxiliadora de la ciudad de Lima, en la cual se encontró una relación negativa y significativa, que sugiere que a menor presencia de burnout existe una mayor calidad de vida profesional.

Suasnabar (2017), realizó una investigación para conocer la relación entre el síndrome de burnout y la calidad de vida profesional en una muestra de 86 enfermeras del Instituto de Enfermedades Neurológicas, en la que los resultados demostraron que existe una relación inversa y significativa entre el síndrome de burnout y la calidad de vida profesional.

Sin embargo, en el análisis elaborado por Rodríguez y Chávez (2018) sobre la relación entre la calidad de vida profesional y síndrome de burnout en una muestra de 90 enfermeras de la clínica Privada Jesús del Norte de la ciudad de Lima, no se encontró una relación significativa entre la calidad de vida profesional y el síndrome de burnout.

En otro estudio realizado en médicos de atención primaria de España, Jorge et al. (2005) encontraron que existe relación entre la calidad de vida profesional y el síndrome de burnout; en el cual los investigadores observaron una mayor correlación entre las demandas en el puesto de trabajo y el cansancio emocional, seguida por la motivación intrínseca y la realización personal; y la calidad de vida profesional frente al agotamiento emocional. Por lo tanto, cuando es mayor la percepción de cargas de trabajo es mayor el agotamiento emocional y la despersonalización; mientras que la percepción de apoyo directivo se asocia directamente 
con la realización personal e inversamente con el agotamiento y la despersonalización, por esto, el apoyo directivo es vital para el óptimo desempeño del colaborador.

De igual manera García et al. (2009) realizaron una investigación en España en un grupo de técnicos de drogodependencia; en el cual se concluyó que la relación entre el síndrome del burnout y la calidad de vida profesional es inversa y significativa. Asimismo, se observó que los resultados para la dimensión agotamiento emocional, fueron positivos sobre las cargas de trabajo y negativos con relación a la motivación intrínseca y el apoyo directivo. Sin embargo, no fueron significativas; mientras que la dimensión despersonalización tuvo un efecto directo en las cargas de trabajo y negativo en la motivación intrínseca.

Por otro lado, en la investigación de Rivera et al. (2016), en médicos residentes en España, se concluyó que existe una relación inversa entre calidad de vida profesional y síndrome de burnout. Por lo tanto, cuando es mayor la percepción de las demandas de trabajo, se incrementa el agotamiento emocional; y cuando es mayor el nivel de motivación intrínseca se incrementa la realización personal en los colaboradores.

Por lo tanto, como señala Patlán (2013), el síndrome de burnout repercute en la calidad de vida personal y laboral de los profesionales; que detectado oportunamente, como afirman Puello et al. (2014) promueve la calidad profesional garantizando la consecución de los objetivos de la organización.

De acuerdo a lo mencionado, se formula la siguiente interrogante ¿Cuál es la relación que existe entre el síndrome de burnout y la calidad de vida profesional en los policías de Lima Metropolitana? En consecuencia, la investigación tiene como objetivo identificar la relación que existe entre el síndrome de burnout y la calidad de vida profesional en el personal de las fuerzas policiales. Al respecto, se espera encontrar una relación negativa entre el síndrome de burnout y la calidad de vida profesional en el personal de las fuerzas policiales 
de Lima metropolitana. Adicionalmente, se espera hallar una relación negativa entre el agotamiento emocional y la calidad de vida profesional, así como una relación negativa entre la despersonalización y la calidad de vida profesional y una relación positiva entre la realización personal y la calidad de vida profesional. Dichas relaciones se encontraron en diversos estudios empíricos, realizados en personal de salud (García et al., 2009; Jorge et al., 2005; Rivera et al., 2016; Vega, Gómez, Caballero \& Contreras, 2017). 


\section{Capítulo 2. Método}

\section{Diseño de Investigación}

Se realizó una investigación de tipo correlación y de diseño transversal. La investigación es correlacional porque busca conocer la relación o asociación existente entre las variables; y de diseño transversal, debido a que la información de la muestra se observó en un solo momento del tiempo (Hernández, Fernández \& Baptista, 2014).

\section{Participantes}

La muestra está compuesta por 200 efectivos policiales de la Policía Nacional del Perú, con diferentes grados policiales (primero, segundo y tercero). Para obtener el tamaño de la muestra se utilizó el programa G*Power (3.1.9.2), que arrojó un muestreo de 193 participantes, dicho cálculo fue realizado considerando un contraste de hipótesis unilateral y un nivel de significancia de .05 , con una potencia de .8 , valor que se considera estándar y con un tamaño del efecto de .2 , ya que al no encontrarse investigaciones que permitan estimar con exactitud el tamaño del mismo, se considera como aceptable (Cárdenas \& Arancibia, 2014).

Para esta investigación, se empleó un muestreo de tipo no probabilístico intencional debido a que, los participantes fueron elegidos a criterio del investigador, de acuerdo a las características de la investigación, por lo cual el procedimiento no se realizó en base a fórmulas de probabilidad, si no que obedeció a los criterios del investigador (Hernández et al., 2014).

El criterio de inclusión considerado para conformar la muestra fue ser policía activo técnico u oficial perteneciente a la ciudad de Lima Metropolitana. Los criterios de exclusión fueron ser estudiantes, jubilados y pertenecer a otra unidad de la Policía Nacional del Perú. 
Los participantes tienen entre los 19 y 60 años de edad $(\mathrm{M}=35.87, \mathrm{DE}=10.82)$. Del total de policiales se observó que el 27.5\% (55) son del género femenino y el 72.5\% (145) del género masculino. En cuanto al estado civil, se encontró que el 38\% (76) son solteros, el 54\% (108) son casados y el 8\% (16) restante son convivientes y divorciados. Asimismo, se apreció que el 25\% (50) no tienen hijos y el 84\% (150) tienen hijos; con respecto al grado policial, se encontró que el 18\% (36) eran de primer grado, el 44\% (88) de segundo grado y el $38 \%$ (76) de tercer grado. Por otro lado, también se obtuvo los resultados referentes a los años y meses que llevan laborando en la institución, obteniendo un mínimo de 9 meses y un máximo de 475 meses (39 años y medio aproximadamente). Adicionalmente, se obtuvo los resultados de las horas de jornada laboral policial, siendo el mínimo de 48 horas (6 días) y el máximo de 96 horas (4 días).

\section{Instrumentos}

\section{Ficha Sociodemográfica}

La ficha sociodemográfica de los Policías pertenecientes a la PNP de Lima fue elaborada para obtener los siguientes datos: edad, género, estado civil, número de hijos, horas de jornada laboral, tiempo que lleva trabajando en la institución, nombre de la posición (cargo) y grado policial (Ver Apéndice B).

Los criterios como la edad, género, número de hijos y estado civil fueron incluidos en el análisis, tal como sugiere la investigación de Aguayo, Vargas, Cañadas y De la Fuente (2017), debido a que fueron considerados como factores relevantes para el desarrollo del burnout en policías a raíz de la revisión de 43 estudios empíricos que examinaron si dichos factores determinaban la aparición de burnout. Con respecto a los criterios horas de jornada laboral, tiempo que lleva trabajando en la institución, carga y grado policial fueron incluidos 
debido a la evidencia teórica encontrada en los estudios realizados por Corredor y Marín (2013) y Sanchez et al. (2013).

\section{Inventario de Burnout de Maslach (Maslach \& Jackson, 1981)}

Para evaluar el síndrome de burnout se empleó el cuestionario de burnout de Maslach en su versión para servicios humanos (MBI - HSS), el cual ha sido aplicado en Perú por Cáceres y Tavera (2013) y en México por Patlán (2013).

El objetivo de este instrumento es medir el fenómeno del burnout. Las dimensiones que evalúa son: agotamiento emocional, la cual cuenta con 9 ítems; despersonalización que cuenta con 5 ítems y realización personal con 8 ítems. Para fines de la presente investigación se utilizará la versión adaptada de Cárdenas (2013) en una muestra de profesionales de diferentes especialidades de la ciudad de Lima.

La prueba tiene un total de 22 preguntas, que se puntúan con una escala tipo Likert; de 7 grados, en un rango del 0 al 6, en donde el 0 representa la categoría "nunca" y el 6 “todos los días". Su aplicación puede ser individual o colectiva y se realiza entre 10 a 15 min (Ver Apéndice C).

Con respecto a las evidencias de validez relacionada a la estructura interna, en el estudio de Cárdenas (2013) se procedió a realizar inicialmente el KMO (Káiser Meyer Olkin) de adecuación de la muestra el cual obtuvo un valor de .85 y la prueba de esfericidad de Barlett fue significativa por contar una probabilidad $(p<.001)$. Como resultado del análisis se obtuvo que sea adecuado realizar un análisis factorial puesto que cumplen con los requisitos para desarrollar dicho análisis, por ello se procedió a realizar el análisis de componentes principales con rotación varimax ya que, los componentes son independientes. 
Como resultado final de este análisis se decidió aplicar una solución factorial de dos componentes, debido a que esta proposición se acerca a la definición de "core of burnout". Los dos componentes explicaron el $39.78 \%$ de la varianza total.

El primer componente obtuvo un autovalor de 5.97 que explica el $27.15 \%$ de la varianza y una carga factorial que oscila en un rango entre .31 y .81 en el cual se agruparon los ítems $(8,2,1,3,14,16,6,13$ y 20) que conformaban la dimensión de agotamiento emocional y los ítems $(11,10,5,15$ y 22) que pertenece a la escala de despersonalización (core of burnout: agotamiento emocional y despersonalización).

En el segundo componente se halló un autovalor de 2.78 que explica el $12.63 \%$ de la varianza y una carga factorial en un rango que oscila entre .45 y .78 y en el cual se agruparon los ítems ( 18,19,4,17,12,7,9 y 21) que conforman la dimensión de realización personal.

Con respecto a la evidencia de confiabilidad, Cárdenas (2013) realizó el análisis de consistencia interna alfa de Cronbach, en el cual se analizaron los ítems de los dos componentes encontrados, los que definen las subescalas. La confiabilidad de la subescala de “core of burnout" (agotamiento emocional y despersonalización) fue de .85 y las correlaciones ítem-test corregidas se encontraron entre .34 y .65. Del mismo modo se calculó la confiabilidad de la subescala realización personal, en la que se encontró un coeficiente de consistencia interna alfa de Cronbach de .77 y las correlaciones obtenidas que oscilan en un rango entre .35 y .68 .

En conclusión, de acuerdo al análisis realizado de dos componentes: core of burnout y realización personal, se demostró que existen requisitos suficientes de validez y confiabilidad para utilizar la prueba en la evaluación del síndrome de burnout en diferentes profesiones. 


\section{Escala de Calidad de Vida Profesional (CVP - 35) (Cabezas, 1998)}

Para la variable calidad de vida profesional se empleará la escala de Calidad de Vida Profesional (CVP - 35) de Cabezas (1998), que cuenta con validez de constructo y confiabilidad y ha sido aplicada en estudios realizados en Colombia, Perú y España (Contreras, Espinosa, Hernández \& Acosta, 2013; Grimaldo, 2010; Tomás-Sábado, 2011).

Para fines de la presente investigación se utilizará la versión adaptada de Grimaldo y Reyes (2014). El objetivo de este instrumento es determinar las categorías de calidad de vida profesional en profesionales de la salud. Las dimensiones que evalúa son: (a) cargas de trabajo que explica lo que el trabajador percibe sobre las demandas del puesto de trabajo, tales como: cantidad de trabajo, presión en las demandas laborales, incomodidad física en el trabajo, prisas y agobios, presión por la realización y el mantenimiento de la calidad de trabajo y los conflictos con otros colaboradores (Grimaldo, 2010; Sánchez, Álvarez \& Lorenzo, 2003); (b) motivación intrínseca hace referencia a la motivación personal, es decir a los recursos internos que establecen la necesidad y la conducta motivada dirigida a la satisfacción del desarrollo de las acciones profesionales, tales como: el tipo de trabajo, la motivación que experimenta, la exigencia de capacitación, el apoyo familiar y las ganas de ser creativo (Grimaldo, 2010; Sánchez et al., 2003) y finalmente (c) apoyo directivo que hace referencia al soporte emocional que brindan los directivos a los trabajadores de la organización, que considera aspectos tales como: la posibilidad de expresión, la satisfacción con el sueldo, el reconocimiento del esfuerzo, la oportunidad de promoción y el apoyo de los superiores (Grimaldo, 2010).

La prueba contiene 33 preguntas, que se responden en una escala del 1 al 10 donde se superponen las categorías: nada (valores 1 y 2), algo (valores 3, 4 y 5), bastante (valores 6,7 y 
8), y mucho (valores 9 y 10). De aplicación individual y colectiva, se realiza en un tiempo aproximado de 15 minutos (Ver Apéndice D).

En cuanto a la validez relacionada a la estructura interna, se realizó el análisis factorial exploratorio mediante el método de extracción de ejes principales y el método de rotación oblicua (Grimaldo \& Reyes, 2014). Previamente se contó con una medida de KMO (Káiser Meyer Olkin) .91 y la prueba de esfericidad de Barlett estadísticamente significativa $(\mathrm{p}<0.001)$. Respecto a la determinación del número de factores, se encontró que tres factores extraídos contenían el 61\% de la varianza de los ítems, es decir, estos factores alcanzaban a explicar con algún grado de significado conceptual las correlaciones entre los ítems Para el primer componente se agruparon los ítems $(1,2,3,4,5,6,7,8,9,10$ y 11$)$ que conforman la dimensión carga en el trabajo, y se observa una carga factorial que oscila en un rango entre .33 y .77. En el segundo componente se agrupan los ítems (12, 13, 14, 15, 16, 17, $18,19,20$ y 21) que corresponden a la dimensión motivación intrínseca, y se observa una carga factorial que oscila en un rango entre -.84 y -.25. Finalmente, el tercer componente está integrado por los ítems $(22,23,24,25,26,27,28,29,30,31,32$ y 33) que integran la dimensión apoyo directivo, y se observa una carga factorial que oscila en un rango entre $.43 \mathrm{y}$ .85 .

El resultado que se observó en el cálculo del coeficiente alfa de Cronbach fue de 95 . Adicionalmente, se encontró un alfa de Cronbach para la dimensión carga laboral de .90, para motivación intrínseca de .91 y por ultimo .95 para apoyo directivo (Grimaldo \& Reyes, 2014). 


\section{Procedimiento}

Para recolectar la información, se presentó una carta a la institución policial en la cual se especificó el objetivo de la investigación y los instrumentos que se utilizarían, así como el tiempo que se emplearía para la ejecución de los mismos. Una vez obtenido el permiso de la institución policial, se coordinó con el encargado de la institución la fecha y horario en el cual se aplicaría los instrumentos de recolección de datos.

Para la presente investigación se realizó un estudio piloto cuya finalidad era saber si el lenguaje utilizado en los instrumentos iba ser de entendimiento para la población a la cual me dirijo, en este caso, efectivos policiales. Al aplicar los instrumentos a una muestra de $(n=33)$ se puede confirmar la comprensión de estos por lo que no fue necesario realizar modificaciones.

Después de aplicado el Piloto, se comprobó que los participantes examinados no refirieron ningún tipo de inconveniente con respecto a los ítems de los cuestionarios. Por lo que, se procedió a la aplicación total de la muestra. Al finalizar el trabajo de campo, se determinó la aplicación y aceptación de 200 participantes $\left(\mathrm{G}^{*}\right.$ Power $\left.=193\right)$.

Seguidamente, se aplicaron los instrumentos al total de policías de la ciudad de Lima. Previamente, se hizo entrega del consentimiento informado, en el que se especifica los criterios de confidencialidad de los resultados (Ver Apéndice A). Una vez recopilados los consentimientos informados que fueron aceptados, se procedió a la entrega de la ficha sociodemográfica y se informaron las instrucciones y el procedimiento para desarrollar los cuestionarios de manera adecuada. Por otro lado, la aplicación se realizó de manera conjunta en 3 grupos distintos. 
Para el óptimo desarrollo de los instrumentos, se consideró que las condiciones del medio ambiente proporcionaran una iluminación adecuada y un espacio alejado de estímulos distractores que pudieran alterar los resultados de los evaluados.

Finalmente, se recogieron los cuestionarios y se codificaron las respuestas, las cuales fueron ingresadas al programa (SPSS Statistics versión 22).

\section{Estrategias de Análisis de Datos}

Para determinar el análisis psicométrico de validez y confiabilidad se esperó encontrar que los datos en el KMO sean mayores o iguales a 0.70 y la prueba de esfericidad de Barlett debe contar una significancia estadística menor que 0.05 . Al contar con el cumplimiento de los dos criterios resultó pertinente realizar un análisis factorial como parte de la evidencias de validez relacionada a la estructura interna; mientras que para le evidencia de confiabilidad de las puntuaciones se utilizó el coeficiente alfa de Cronbach.

Por otro lado, en cuanto a la prueba de normalidad se utilizará la prueba de Kolmogorov por contarse con una muestra mayor a 50 participantes. De acuerdo el resultado obtenido se determinó que los datos se analizarán con un estadístico paramétrico o no paramétrico. En caso se encuentren resultados que se alejen a una distribución se utilizará la prueba de Spearman, caso contrario se utilizará la prueba de Pearson. 


\section{Capítulo 3. Resultados}

\section{Evidencias de Validez y Confiabilidad de los Instrumentos}

Con el fin de reportar las evidencias de validez y confiabilidad, se realizaron los análisis psicométricos del Inventario de Burnout de Maslach y de la Escala de Calidad de Vida Profesional; donde se analizará la validez relacionada a la estructura interna de ambos instrumentos mediante el análisis factorial exploratorio (AFE). Asimismo, se reportará la confiabilidad de las dimensiones de ambos instrumentos con la finalidad de conocer la consistencia interna de las puntuaciones obtenidas mediante el coeficiente alfa de Cronbach.

Para demostrar la evidencia de validez del MBI (1981) se analizó la estructura interna por medio de un análisis factorial exploratorio con factorización de ejes principales con el objetivo de conocer cuántos factores pueden representar la variable; y con rotación oblimin, que se realiza para dimensiones que teóricamente se espera que correlacionen entre sí (Ferrando \& Anguiano-Carrasco, 2010). Por otro lado, la confiabilidad fue calculada mediante el coeficiente de consistencia interna alfa de Cronbach.

En primer lugar, se procedió a realizar un análisis de la estructura interna del Inventario de Burnout de Maslach, utilizando el análisis factorial exploratorio (AFE). Previamente, se evalúa el grado de relación conjunta entre las variables debido a que es una condición necesaria para aplicar el AFE.

Para ello, se utilizó el test de Kaiser Meyer Olkin (KMO), que evalúa hasta qué punto las puntuaciones de cada variable se pueden predecir a partir de las otras. Por otro lado, la prueba de esfericidad de Barlett sirve para contrastar la hipótesis nula de que no existe una relación entre las variables (Ferrando \& Anguiano-Carrasco, 2010). 
El análisis preliminar de los ítems arrojó un KMO de .86, el cual es superior a .80 que es el valor mínimo recomendado (Kaiser como se citó en Ferrando \& Anguiano-Carrasco, 2010); y la prueba de esfericidad de Bartlett tuvo un valor $p<.001$, el cual es menor a .05 lo que demuestra que es estadísticamente significativa. Los resultados y valores obtenidos indicaron que es adecuado realizar un análisis factorial al cumplirse con los requisitos para desarrollar dicho análisis y por demostrarse cierto grado de relación entre los ítems.

Como primer resultado del análisis factorial, se hallaron seis componentes, con autovalores mayores a 1 que explicaron un $46.46 \%$ de la varianza total. Dicha solución no es interpretable, por la dispersión que presentaron los ítems, debido a que varios de los componentes están definidos en su mayoría por dos ítems o no tienen relación con los ítems que componen la solución. Por ello, se procedió a realizar un segundo análisis de ejes principales con rotación oblimin, considerando tres factores como sugirió el gráfico de sedimentación, de acuerdo a la solución factorial planteada originalmente por la prueba (Ver Figura 1).

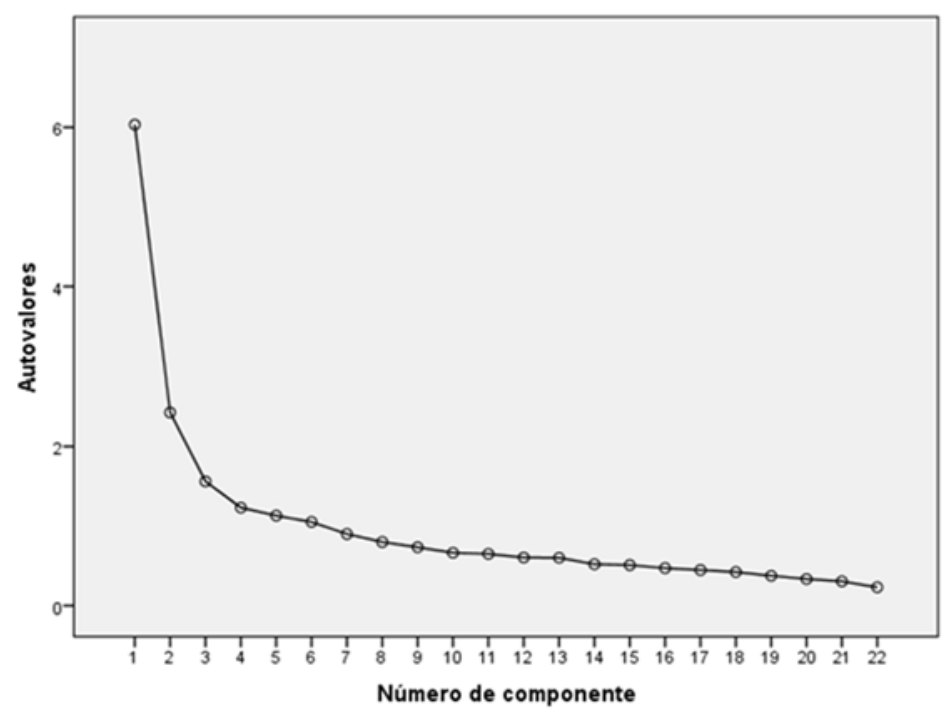

Figura 1. Gráfico de sedimentación de Cattel del MBI. 
De los tres factores extraídos, el primer factor presentó un autovalor de 5.48 que explica el $24.91 \%$ de la varianza, y en el que se agrupan los ítems que conforman el componente de agotamiento emocional a excepción de los ítems $(22,5,15$ y 11$)$ que pertenecen a la escala despersonalización. El segundo factor presentó un autovalor de 1.77 que explica el $8.04 \%$ de la varianza, y en el que se agruparon en su totalidad los ítems de la escala realización personal. El tercer factor presentó un autovalor de .95 que explica el 4.3\% de la varianza, y el que se agruparon los ítems que en su mayoría estimaban el componente de agotamiento emocional, a excepción de dos ítems (4 y 10) que pertenecían a las escalas de realización personal y despersonalización. Sin embargo, al revisar la matriz patrón, se observó que los ítems se cargaron en dimensiones a las cuales no pertenecen originalmente (Ver Apéndice E). Por ello, se realizó un análisis factorial considerando dos dimensiones.

En este último análisis factorial, de los dos factores extraídos, se obtuvo que la primera dimensión presentó un autovalor de 5.43 que explica el $24.91 \%$ de la varianza e ítems con cargas factoriales en un rango de .27 y .77 y en el que se agrupan los ítems $(1,2,3,6,8,13,14,16,20)$ que originalmente formaban parte de la dimensión de agotamiento emocional y los ítems $(5,10,11,15$ y 22), que integraban originalmente la dimensión de despersonalización. Por el resultado obtenido del análisis de ejes principales se demostró que el componente tres está conformado por ítems que pertenecen a la escala de agotamiento emocional y despersonalización; por ello, se renombró la dimensión a “Distanciamiento emocional”. La segunda dimensión, arrojó un autovalor de 1.73 que explica el $7.86 \%$ de la varianza e ítems con una carga factorial en un rango que oscila entre .36 y .52 , siendo estas consideradas aceptables al superar el valor mínimo recomendado de .30 (Ferrando \& Anguiano, 2010). Este factor está conformado por los ítems (4, 7, 9, 12, 17, 18, 19 y 21) que originalmente forman parte de la dimensión realización personal (Ver Tabla 1). 
Tabla 1

Cargas factoriales del análisis factorial exploratorio del Inventario de Burnout de Maslach

\begin{tabular}{|c|c|c|c|}
\hline \multirow[b]{2}{*}{ Ítems } & \multicolumn{3}{|c|}{ Factor } \\
\hline & $\begin{array}{l}\text { Distanciamiento } \\
\text { Emocional }\end{array}$ & $\begin{array}{l}\text { Realización } \\
\text { Personal }\end{array}$ & $\begin{array}{l}\text { Correlació } \\
\text { n Ítem- } \\
\text { Test- } \\
\text { corregida }\end{array}$ \\
\hline 8. Me siento agotado por el trabajo. & 0.77 & & 0.66 \\
\hline $\begin{array}{l}\text { 1. Debido a mi trabajo me siento } \\
\text { emocionalmente agotado. }\end{array}$ & 0.77 & & 0.64 \\
\hline $\begin{array}{l}\text { 3. Me encuentro cansado cuando me levanto por } \\
\text { las mañanas y tengo que... }\end{array}$ & 0.75 & & 0.69 \\
\hline 2. Al final de la jornada me siento agotado. & 0.67 & & 0.54 \\
\hline $\begin{array}{l}\text { 14. Siento que estoy haciendo un trabajo } \\
\text { demasiado duro. }\end{array}$ & 0.61 & & 0.58 \\
\hline $\begin{array}{l}\text { 16. Trabajar en contacto directo con las personas } \\
\text { me produce.... }\end{array}$ & 0.59 & & 0.58 \\
\hline 13. Me siento frustrado por mi trabajo. & 0.57 & & 0.57 \\
\hline $\begin{array}{l}\text { 11. Me preocupa que este trabajo me esté } \\
\text { endureciendo emocionalmente. }\end{array}$ & 0.55 & & 0.53 \\
\hline $\begin{array}{l}\text { 10. Creo que me comporto de manera más } \\
\text { insensible con .... }\end{array}$ & 0.52 & & 0.5 \\
\hline $\begin{array}{l}\text { 6. Trabajar con personas todos los días es una } \\
\text { tensión para mí. }\end{array}$ & 0.52 & & 0.51 \\
\hline $\begin{array}{l}\text { 5. Creo que trato a algunas personas con } \\
\text { indiferencia. }\end{array}$ & 0.5 & & 0.49 \\
\hline $\begin{array}{l}\text { 22. En mi trabajo, me incomoda que las } \\
\text { personas me interrumpan por sus problemas... }\end{array}$ & 0.5 & & 0.48 \\
\hline $\begin{array}{l}\text { 20. En el trabajo siento que he llegado al límite } \\
\text { de mis posibilidades. }\end{array}$ & 0.43 & & 0.43 \\
\hline $\begin{array}{l}\text { 15. Trato de mantenerme al margen de los } \\
\text { problemas personales de los demás. }\end{array}$ & 0.27 & & 0.27 \\
\hline $\begin{array}{l}\text { 17. Tengo facilidad para crear un ambiente } \\
\text { relajado para los demás. }\end{array}$ & & 0.52 & 0.46 \\
\hline $\begin{array}{l}\text { 7. Me enfrento muy bien a los problemas que me } \\
\text { enfrentan los demás. }\end{array}$ & & 0.5 & 0.44 \\
\hline $\begin{array}{l}\text { 9. Siento que mediante mi trabajo estoy } \\
\text { influyendo positivamente... }\end{array}$ & & 0.5 & 0.4 \\
\hline $\begin{array}{l}\text { 21. Siento que se trata de forma adecuada los } \\
\text { conflictos emocionales en el trabajo. }\end{array}$ & & 0.49 & 0.38 \\
\hline $\begin{array}{l}\text { 19. He realizado muchas cosas que valen la pena } \\
\text { en este trabajo. }\end{array}$ & & 0.47 & 0.43 \\
\hline $\begin{array}{l}\text { 4. Puedo entender con facilidad lo que piensan } \\
\text { las personas. }\end{array}$ & & 0.4 & 0.28 \\
\hline 12. Me encuentro con mucha vitalidad. & & 0.38 & 0.4 \\
\hline $\begin{array}{l}\text { 18. Me encuentro animado después de trabajar } \\
\text { junto con mis clientes. }\end{array}$ & & 0.36 & 0.38 \\
\hline
\end{tabular}


Una vez realizado el análisis de validez, se procedió a realizar el análisis de confiabilidad de las puntuaciones, por el método de consistencia interna. Para medir la consistencia interna de los ítems se usó el coeficiente de alfa de Cronbach para cada una de las dimensiones a hallar mediante el análisis factorial. El valor del alfa, debe ser igual o mayor a .70 y las correlaciones ítem - test corregidas mayor o igual .20 (Kline como se citó en Tapia \& Luna, 2010). En la dimensión distanciamiento emocional se encontró un alfa de Cronbach de .87, el cual es considerado aceptable. En cuanto a la correlación ítem - test corregida muestra un rango entre .27 y .69, encontrándose dentro del límite permitido. En cuanto al factor realización personal se encontró un alfa de Cronbach de .70, que es considerado aceptable. En cuanto a la correlación ítem - test corregida muestra un rango entre .28 y .46 mostrando valores aceptables (Ver Tabla 1).

En segundo lugar, se analizaron las propiedades psicométricas de la Escala de Calidad De Vida Profesional (1998), y para demostrar la evidencia de validez se analizó la estructura interna por medio del análisis factorial exploratorio con factorización de ejes principales con rotación oblimin; y la confiabilidad fue calculada mediante el coeficiente de consistencia interna alfa de Cronbach.

El análisis preliminar de los ítems mostró que el test de Kaiser Meyer Olkin (KMO) de adecuación de la muestra alcanzó un valor de .92, muy superior al valor mínimo recomendado; y la prueba de esfericidad de Bartlett fue significativa por contar una probabilidad $(p<.001)$. Con los resultados y valores obtenidos se puede afirmar que los ítems se encuentran relacionados y se puede proceder a realizar un análisis factorial.

Como primer resultado del análisis, se hallaron cinco componentes, con autovalores mayores a 1 que explicaron un 57.70\% de la varianza total. Debido a que el cuarto y quinto factor extraído solo contienen dos ítems, dicha solución no podría ser interpretada. Por ello, 
se procedió a realizar un segundo análisis de ejes principales con rotación oblimin, considerando tres factores como sugirió el gráfico de sedimentación de acuerdo a la solución factorial planteada originalmente por la prueba (Ver Figura 2).

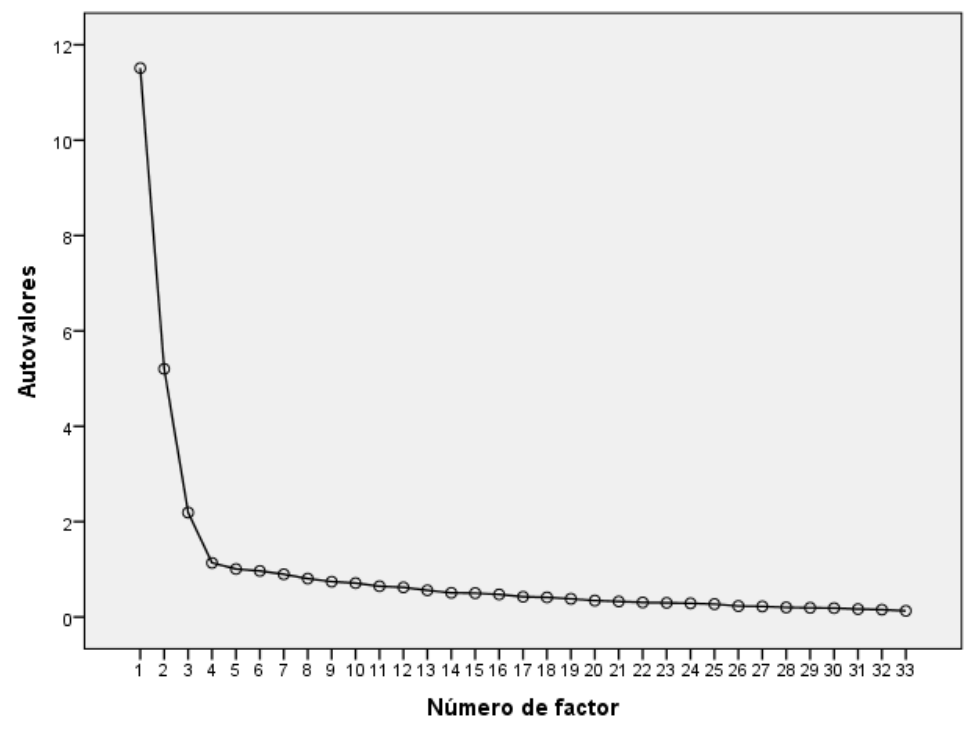

Figura 2. Gráfico de sedimentación de Cattel del CVP - 35

En el último análisis factorial, de los tres factores extraídos, se obtuvo que el primer factor presentó un autovalor de 11.09 que explica el 33.61\% de la varianza e ítems con cargas factoriales en un rango de .51 y .83 valor considerado aceptable (Ferrando \& Anguiano, 2010); y se encuentra conformado por los ítems $(22,23,24,25,26,27,28,29,30,31,32,33)$ que integran el componente apoyo directivo, a excepción del ítem (21) que pertenece a la escala de motivación intrínseca, dicho ítem por constructo teórico fue considerado como parte de la dimensión apoyo directivo. El segundo factor presentó un autovalor de 4.70 que explica el $14.23 \%$ de la varianza e ítems con cargas factoriales en un rango de .47 y .74, valor considerado aceptable; y está constituido por los ítems $(1,2,3,4,5,6,7,8,9,10$ y 11$)$ que conforman la dimensión carga en el trabajo. Finalmente, el tercer factor presentó un autovalor 1.74 que explica el $5.27 \%$ de la varianza e ítems con cargas factoriales en un rango de $.50 \mathrm{y}$ 
.78 valor considerado aceptable; y está compuesto por los ítems $(12,13,14,15,16,17,18,19$ y 20) que pertenecen a la dimensión motivación intrínseca (Ver Tabla 2). 
Tabla 2

Cargas factoriales del análisis factorial exploratorio de la Escala de Calidad de Vida Profesional

\begin{tabular}{|c|c|c|c|c|}
\hline \multirow[b]{2}{*}{ Ítems } & \multicolumn{4}{|c|}{ Factor } \\
\hline & $\mathrm{AD}$ & $\mathrm{CT}$ & MI & $\begin{array}{c}\text { Correlación } \\
\text { İtem- Test- } \\
\text { corregida }\end{array}$ \\
\hline 25.La posibilidad de ser promocionado(a) & .83 & & & .73 \\
\hline 26. El apoyo de mi jefes & .82 & & & .77 \\
\hline $\begin{array}{l}\text { 29. La institución donde trabajo trata de mejorar la } \\
\text { calidad de vida de mi puesto. }\end{array}$ & .82 & & & .76 \\
\hline $\begin{array}{l}\text { 33. La posibilidad de ser escuchado(a), cuando } \\
\text { realizo alguna propuesta. }\end{array}$ & .78 & & & .80 \\
\hline 24. El reconocimiento de mi esfuerzo. & .78 & & & .75 \\
\hline $\begin{array}{l}\text { 28. Recibo información de los resultados de mi } \\
\text { trabajo. }\end{array}$ & .77 & & & .78 \\
\hline 30. Tengo autonomía o libertad de decisión. & .76 & & & .76 \\
\hline 27. El apoyo de mis compañeros(a). & .72 & & & \\
\hline 31. La variedad en mi trabajo. & .67 & & & .77 \\
\hline 23. Satisfacción con el sueldo. & .62 & & & .59 \\
\hline 21. El apoyo que recibo de mi equipo. & .59 & & & .72 \\
\hline 22. Posibilidad de expresar lo que siento y necesito. & .54 & & & .70 \\
\hline 32. La posibilidad de ser creativo. & .51 & & & .71 \\
\hline 10. El estrés que tengo (esfuerzo emocional). & & .74 & & .74 \\
\hline 7. La incomodidad física en el trabajo. & & .73 & & .65 \\
\hline $\begin{array}{l}\text { 2. Prisas y agobios por la falta de tiempo para realizar } \\
\text { mi trabajo. }\end{array}$ & & .72 & & .67 \\
\hline 9. Las interrupciones molestas. & & .71 & & .67 \\
\hline $\begin{array}{l}\text { 11. Mi trabajo tiene consecuencias negativas para mi } \\
\text { salud. }\end{array}$ & & .66 & & .66 \\
\hline $\begin{array}{l}\text { 3. Presión que recibo para realizar la cantidad de } \\
\text { trabajo que tengo. }\end{array}$ & & .65 & & .69 \\
\hline $\begin{array}{l}\text { 4. Presión que recibo para mantener la calidad de mi } \\
\text { trabajo. }\end{array}$ & & .60 & & .60 \\
\hline 6. La falta de tiempo para mi vida personal. & & .59 & & .59 \\
\hline 8. La carga de responsabilidad. & & .56 & & .55 \\
\hline $\begin{array}{l}\text { 5. Los conflictos que tengo con otras personas de mi } \\
\text { trabajo. }\end{array}$ & & .47 & & .43 \\
\hline 1. Cantidad de trabajo que tengo. & & .47 & & .39 \\
\hline 16. Mis ganas de ser creativo. & & & .78 & .75 \\
\hline 19. Me siento orgulloso(a) de mi trabajo. & & & .74 & .76 \\
\hline $\begin{array}{l}\text { 13. La motivación que experimento (ganas de } \\
\text { esforzarme). }\end{array}$ & & & .72 & .68 \\
\hline $\begin{array}{l}\text { 17.- La capacitación que tengo para hacer mi trabajo } \\
\text { actual. }\end{array}$ & & & .67 & .68 \\
\hline $\begin{array}{l}\text { 18. Mi trabajo es importante para la vida de otras } \\
\text { personas. }\end{array}$ & & & .67 & .64 \\
\hline 15. El apoyo de mi familia. & & & .66 & .61 \\
\hline 20. Lo que tengo que hacer queda claro. & & & .66 & .65 \\
\hline 12. Satisfacción con el tipo de trabajo. & & & .58 & .58 \\
\hline $\begin{array}{l}\text { 14. La exigencia de capacitación para realizar mi } \\
\text { trabajo. }\end{array}$ & & & .50 & .52 \\
\hline
\end{tabular}

Nota: $\mathrm{AD}=$ Apoyo directivo, $\mathrm{CD}=$ Carga de trabajo, $\mathrm{MI}=$ Motivación intrínseca 
Al finalizar el análisis de validez, se procedió a realizar por el método de consistencia interna el análisis de confiabilidad de las puntuaciones mediante el alfa de Cronbach y las correlaciones ítems- test corregida por cada dimensión, las cuales se presentan en la Tabla 7. La dimensión carga de trabajo presenta un alfa de Cronbach de .89, mostrando una consistencia interna mayor a lo aceptable. En cuanto a la correlación ítem-test corregida muestra un rango entre .39 y .74, encontrándose dentro de los límites permitidos.

En cuanto a la dimensión motivación intrínseca se encontró un alfa de Cronbach de .89 , mostrando estar por encima de lo aceptable. En cuanto a la correlación ítem - test corregida muestra un rango entre .52 y .76 mostrando valores aceptables.

Con respecto al factor apoyo directivo se encontró un alfa de Cronbach de .95, mostrando una consistencia interna mucha más elevada a lo aceptable. En cuanto a la correlación ítem - test corregida muestra un rango entre .59 y .80 mostrando valores aceptables.

Luego del estudio psicométrico de los instrumentos, se procedió a realizar los análisis de los estadísticos descriptivos y el análisis de normalidad con el fin de seleccionar la prueba estadística de correlación más adecuada para analizar la relación entre las variables síndrome de burnout y calidad de vida profesional.

En la Tabla 3, se encontró que el valor promedio obtenido para la dimensión Distanciamiento emocional, evidencia que el total de participantes han obtenido puntajes cercanos al mínimo esperado. Seguidamente, el coeficiente de variación nos indica la existencia de una dispersión alta, por lo que algunos puntajes estarían más alejados del promedio, por ende, los datos son heterogéneos. Por otro lado, en la dimensión Realización Personal se observa que el valor promedio obtenido es alto y el coeficiente variación tiene un 
valor bajo. En consecuencia, se evidencia una baja dispersión; por lo tanto los datos son homogéneos.

Con respecto a las tres dimensiones de Calidad de Vida Profesional, se observa que la Motivación Intrínseca es la que presenta mayor promedio, encontrándose más cercana al puntaje máximo; y el coeficiente de variación nos indica una baja dispersión, por ende, los datos son homogéneos. Por el contrario, en la dimensión carga de trabajo se evidencia que el total de participantes han obtenido puntajes cercanos al mínimo esperado. Por otro lado, el coeficiente de variación nos indica la existencia de una dispersión alta, por lo que algunos puntajes estarían más alejados del promedio, por ende, los datos son heterogéneos.

Tabla 3

Estadísticos descriptivos de la variable Síndrome de Burnout y Calidad de Vida Profesional

\begin{tabular}{|c|c|c|c|c|c|}
\hline & Mínimo & Máximo & $\mathrm{M}$ & $\mathrm{DE}$ & $\mathrm{CV}$ \\
\hline $\begin{array}{l}\text { Distanciamiento } \\
\text { Emocional }\end{array}$ & .00 & 5.29 & 1.62 & 1.24 & $76.54 \%$ \\
\hline $\begin{array}{l}\text { Realización } \\
\text { Personal }\end{array}$ & 1.50 & 6.00 & 4.77 & 1.09 & $22.85 \%$ \\
\hline $\begin{array}{l}\text { Apoyo } \\
\text { Directivo }\end{array}$ & 1.00 & 10.00 & 6.36 & 2.17 & $34.12 \%$ \\
\hline $\begin{array}{l}\text { Carga de } \\
\text { trabajo }\end{array}$ & 1.00 & 9.91 & 4.47 & 1.89 & $42.28 \%$ \\
\hline $\begin{array}{l}\text { Motivación } \\
\text { Intrínseca }\end{array}$ & 1.78 & 10.00 & 7.85 & 1.80 & $22.93 \%$ \\
\hline
\end{tabular}




\section{Análisis Correlacional}

Seguidamente, se evaluó la normalidad de los puntajes a través de la prueba de Kolmogorov - Smirnov, con la finalidad de identificar el estadístico más adecuado para analizar la relación entre el síndrome de burnout y la calidad de vida profesional. Se encontró que los factores del síndrome de burnout no se aproximan a una distribución normal $(p<.001)$. De manera similar, el factor motivación intrínseca de calidad de vida profesional no se aproxima a una distribución normal; mientras que los factores apoyo directivo y carga de trabajo se aproximan a una distribución normal $(p>.05)$. Por lo tanto, con dicho resultados se determinó que el estadístico a utilizar es la correlación de Spearman y solamente para el caso apoyo directivo y carga de trabajo se empleara la correlación de Pearson (Ver Tabla 4).

Tabla 4.

Prueba de Normalidad de las Variables Síndrome de Burnout y Calidad de Vida Profesional

\begin{tabular}{lcc}
\hline \multicolumn{1}{c}{ Variables } & Estadístico & Sig. \\
\hline Distanciamiento Emocional & .13 & $<.001$ \\
Realización Personal & .15 & $<.001$ \\
Apoyo Directivo & .06 & $>.05$ \\
Carga de trabajo & .06 & $>.05$ \\
Motivación Intrínseca & .13 & $<.001$ \\
\hline
\end{tabular}

En el análisis de correlación se encontró que la dimensión distanciamiento emocional muestra una relación negativa y significativa con el apoyo directivo $\left(r_{s}=-.43 ; p<.001\right)$ y la motivación intrínseca $\left(r_{s}=-.35 ; p<.001\right)$; y por el contrario una relación positiva con carga de trabajo $\left(r_{s}=.59 ; p<.001\right)$. Por lo tanto, un mayor distanciamiento emocional está asociado a un menor apoyo directivo y motivación intrínseca por parte de los efectivos 
policiales; mientras que un mayor distanciamiento emocional está relacionado a una mayor percepción de carga de trabajo. Por otro lado, se encontró una correlación positiva y significativa entre la dimensión realización personal con el apoyo directivo $\left(r_{s}=.35 ; p<\right.$ .001) y la motivación intrínseca $\left(r_{s}=.44 ; p<.001\right)$; mientras que la relación con carga de trabajo fue negativa y significativa $\left(r_{s}=-.14 ; p<.05\right)$. En consecuencia, a mayor realización personal se aprecia mayor motivación intrínseca y apoyo directivo por parte de la institución policial; no obstante a mayor realización personal se percibe menor carga de trabajo.

Seguidamente, se analizó la correlación de los factores con las variables sociodemográficas. Se encontró que la edad se encuentra asociada de manera negativa y significativa con las dos dimensiones del burnout, distanciamiento emocional $\left(r_{s}=-.13 ; p<.05\right)$ y realización personal $\left(r_{s}=-.19 ; p<.01\right)$. Asimismo, con respecto a la calidad de vida profesional se observó una relación negativa y significativa con la dimensión carga de trabajo $\left(r_{s}=-.13 ; p<.05\right)$. Por lo tanto, a mayor edad se percibe menor distanciamiento emocional y realización personal. Asimismo, los efectivos policiales con mayor edad perciben menor carga de trabajo. Por otro lado, en cuanto al número de hijos, se encontró únicamente una relación negativa y significativa con la realización personal $\left(r_{s}=-.13 ; p<.05\right)$; es decir, a mayor número de hijos se presenta menor realización personal. Por otro parte, con respecto al tiempo que los efectivos policiales llevan trabajando en la institución se encontró una correlación negativa y significativa con la realización personal $\left(r_{s}=-.17 ; p<.01\right)$ y la carga de trabajo $\left(r_{s}=-.13 ; p<.05\right)$; lo que implica que a mayor tiempo de servicio se percibe una menor realización personal y carga laboral. Por último, en cuanto a las horas de jornada laboral se observó una correlación positiva y significativa con la realización personal $\left(r_{s}=.13 ; p<.05\right)$, el apoyo directivo $\left(r_{s}=.14 ; p<.05\right)$ y la motivación intrínseca $\left(r_{s}=.23 ; p<.01\right)$. No obstante, se encontró una correlación negativa y significativa con el distanciamiento emocional 
$\left(r_{s}=-.22 ; p<.01\right)$; por lo tanto, una mayor jornada laboral se relaciona con una mayor realización personal, motivación intrínseca y apoyo directivo; y una mayor jornada laboral se asocia con un menor distanciamiento emocional (Ver Tabla 5).

\section{Tabla 5}

Matriz de correlación de las variables Síndrome de Burnout y Calidad de Vida Profesional y Variables Sociodemográficas

\begin{tabular}{|c|c|c|c|c|c|c|c|c|c|}
\hline & 1 & 2 & 3 & 4 & 5 & 6 & 7 & 8 & 9 \\
\hline 1.DE & 1 & & & & & & & & \\
\hline 2.RP & $-.28^{* * *}$ & 1 & & & & & & & \\
\hline 3. $\mathrm{AD}$ & $-.43^{* * *}$ & $.35^{* * *}$ & 1 & & & & & & \\
\hline 4. $\mathrm{CD}$ & $.59^{* * *}$ & $-.14^{*}$ & $-.40^{* * *}$ & 1 & & & & & \\
\hline 5. MI & $-.35^{* * *}$ & $.44^{* * *}$ & $.56^{* * *}$ & -.07 & 1 & & & & \\
\hline 6.Edad & $-.13^{*}$ & $-.19^{* *}$ & .05 & $-.13^{*}$ & -.08 & 1 & & & \\
\hline 7.Número de Hijos & -.08 & $-.13^{*}$ & -.02 & -.04 & -.03 & $.78^{* * *}$ & 1 & & \\
\hline $\begin{array}{l}\text { 8.Tiempo que lleva } \\
\text { trabajando }\end{array}$ & -.10 & $-.17^{* *}$ & .01 & $-.13^{*}$ & -.10 & $.96^{* * *}$ & $.76^{* * *}$ & 1 & \\
\hline $\begin{array}{l}\text { 9.Horas de jornada } \\
\text { laboral }\end{array}$ & $-.22^{* *}$ & $.13^{*}$ & $.14^{*}$ & -.09 & $.23^{* *}$ & .04 & .07 & .05 & 1 \\
\hline
\end{tabular}

Nota: $\mathrm{DE}=$ Distanciamiento Emocional, $\mathrm{RP}=$ Realización Personal, $\mathrm{AD}=$ Apoyo Directivo, $\mathrm{CD}=$ Carga de Trabajo, $\mathrm{MI}=$ Motivación $* * * p<.001, * * p<.01,{ }^{*} p<.05$ 


\section{Capítulo 4. Discusión}

El propósito de la presente investigación fue conocer la relación entre el síndrome de burnout y la calidad de vida profesional en Policías de Lima Metropolitana. Para ello se realizó un estudio de tipo correlacional y de diseño transversal, en una muestra que estuvo conformada por 200 efectivos policiales de ambos géneros con edades entre 19 y 60 años.

Para alcanzar el objetivo de la investigación, se procedió a realizar los análisis psicométricos de los instrumentos empleados. Para el inventario de burnout se realizó el análisis de validez de constructo de la prueba mediante el análisis de ejes principales, en el cual se encontró que la solución factorial óptima para medir el burnout era de dos componentes: distanciamiento emocional (agotamiento emocional y despersonalización) y realización personal. De manera similar, en algunos estudios se unieron las dos dimensiones que miden el burnout de manera directa para obtener una mayor consistencia estadística debido a la debilidad de los factores (Cárdenas, 2013; Grajales, 2000).

Para el inventario de calidad de vida profesional se procedió a realizar el análisis de validez de constructo de la prueba mediante el análisis ejes principales, en el cual se encontró una solución factorial de tres componentes, de acuerdo a la solución planteada originalmente por la prueba de Cabezas (como se citó en Grimaldo, 2010). Del mismo modo, en la investigación de Contreras et al. (2013) se plantea una solución factorial de tres factores.

Por otro lado, en relación al cumplimiento de la hipótesis se encontró que se cumplen de manera parcial, al no encontrarse una relación positiva y significativa entre todas las dimensiones. En primer lugar, se encontró una relación positiva y significativa entre el distanciamiento emocional (agotamiento emocional y despersonalización) y la carga de trabajo en los efectivos policiales. De manera similar, en algunos estudios internacionales realizados en personal de salud, se encontró que una mayor carga de trabajo (incremento en 
las horas de jornada laboral y tareas), origina la pérdida de energía mental y física, reduciendo el interés del colaborador en cumplir sus funciones, lo que deteriora el servicio que ofrecen a los pacientes (García et al., 2009; Vega, Gómez, Caballero \& Contreras, 2017). De igual manera, en una investigación nacional realizada en una muestra de enfermeras, se encontró un correlación directa y significativa entre la despersonalización y la carga de trabajo (Suasnabar, 2017).De acuerdo a lo mencionado, en el personal policial, la mayor asignación de demandas laborales, deteriora los recursos emocionales y físicos para afrontarlas (Romero, 2015); en consecuencia surgen dificultades en las relaciones laborales, decisiones ineficientes, ironía y cansancio laboral (Corredor \& Marín, 2013). Por lo tanto, la institución policial debería gestionar los recursos humanos para compensar las demandas de trabajo a través de diferentes tipos de incentivos (Euwema, Kop \& Bakker, 2004), como la implementación de una adecuada administración de la carga laboral para reducir el cansancio emocional originado por el síndrome de burnout (Vega, Gómez, Caballero \& Contreras, 2017).

Por el contrario, se encontró una relación negativa y significativa entre distanciamiento emocional (agotamiento emocional y despersonalización) y la motivación intrínseca. De igual manera, en los estudios realizados en personal de salud, se encontró que un menor nivel de motivación personal incrementa el cansancio emocional; por lo que se observa un menor interés por el trabajo cuando existe una mayor fatiga emocional, desinterés y aislamiento, generando el deterioro de la productividad y de la calidad del servicio (García et al., 2009; Vega, Gómez, Caballero \& Contreras, 2017). Los resultados encontrados resaltan que el mayor cansancio emocional del personal policial originado por el desgaste psicológico y el agotamiento físico, promueven conductas disfuncionales que se intensifican por la pérdida de motivación intrínseca y falta de satisfacción laboral, que conducen al ausentismo laboral, evasión del puesto y retrasos en el cumplimiento de tareas (Durán \& Montalbán, 
2000). Tal como propone la investigación de Zárate (2017) en la que se observa una relación inversa, entre la satisfacción laboral con el distanciamiento emocional y la realización personal. De manera similar, la disminución de la autoestima, irritabilidad, depresión, impotencia y ansiedad que experimenta el colaborador emocionalmente agotado, puede originar aislamiento social e incapacidad de abandonar el rol profesional fuera del ámbito laboral (Hogarth, 2017). Adicionalmente, el estado permanente de emociones negativas (agresividad, ira y frustración) que adoptan los policías cuando ejercen coerción sobre los criminales, incrementa la despersonalización deteriorando la motivación intrínseca (Schaible $\&$ Six, 2016). Por lo tanto, un mayor nivel de emociones negativas y un menor nivel de emociones positivas, inducen a que los agentes de la policía se sientan menos involucrados con su trabajo, originando el desinterés por el cumplimiento de sus funciones (Basinska et al., 2014).

Del mismo modo, se encontró una relación negativa y significativa entre el distanciamiento emocional y el apoyo directivo. Igualmente, en los estudios internacionales realizados en una muestra de personal de salud, se encontró que los profesionales que reciben mayor apoyo directivo presentan menor agotamiento emocional y mayor interés por su trabajo (García et al., 2009; Vega, Gómez, Caballero \& Contreras, 2017). En tal sentido, un estudio nacional sugiere que clima laboral afecta significativamente el agotamiento emocional de los policías (García, 2016). Por lo cual, a partir de estos resultados, se infiere que los factores de carácter organizativo tales como: la falta de soporte emocional de los directivos a los colaboradores de la institución, la inequidad en las oportunidades de ascenso y la insatisfacción con la remuneración incrementan la fatiga emocional y falta de interés por su trabajo (Grimaldo, 2010; Sánchez et al., 2001), genera emociones contradictorias en el efectivo policial, debido a que por las demandas emocionales, es decir no expresar sus emociones, impuestas en el cumplimiento de su rol organizacional y cultural de protección a 
la sociedad, se incrementa al agotamiento emocional. A su vez, las demandas de su rol organizacional de mantener la estabilidad y control en las situaciones de emergencia, se oponen a la expresión de sus emociones frente a episodios traumáticos aumentando su nivel de despersonalización (Schaible \& Six ,2016).

Además, se encontró una relación negativa y significativa entre la realización personal y la carga de trabajo. De manera similar, en algunos estudios en personal de salud, se encontró que el incremento en las demandas laborales disminuye la satisfacción personal y el interés por alcanzar logros profesionales (García et al., 2009; Jorge et al., 2005). De igual modo, en el personal policial el aumento de las exigencias laborales, genera que los policías perciban un desequilibrio entre la presión ejercida sobre ellos y la percepción de baja capacidad de respuesta que afecta el cumplimiento de las tareas. Adicionalmente, la falta de autonomía para resolver dichas demandas, propias de las características estructurales de la institución policial de ser un entorno jerárquico de mando descendente, rígido y cerrado, disminuye el entusiasmo e iniciativa de los subordinados, que incrementa el nivel de estrés deteriorando el desempeño del policía y contribuyendo a la aparición del síndrome de burnout (Durán \& Montalbán, 2000; Gong \& Zhang, 2015). Sin embargo, estos resultados se contradicen con los encontrados en el estudio de Vega et al. (2017), en el que se observó que el incremento en la carga laboral no afecta el desempeño del colaborador cuando existen altos niveles de realización personal, ya que, presenta un mayor compromiso con la organización.

Por otro lado, se encontró una relación positiva y significativa entre realización personal y la motivación intrínseca. De la misma forma, diversos estudios internacionales realizados en personal de salud, manifiestan que los trabajadores presentan mayor interés por alcanzar logros personales y profesionales cuando la motivación personal es mayor (García et al., 2009; Jorge et al., 2005; Rivera et al., 2016; Vega et al., 2017). De forma similar, el estudio de Suasnabar (2017) realizada en el Perú, confirma que la falta de realización 
personal afecta la motivación intrínseca del personal de enfermería. En este sentido, los policías que presentan mayores niveles de realización personal manifiestan actitudes más favorables para solucionar los conflictos, debido a su mayor motivación (Mikkelsen \& Burke, 2004), la cual incentivaría su creatividad y conducta de adaptación a las demandas que se presentan en la organización (Rivera et al., 2016). Por lo tanto, un menor nivel de burnout y elevado compromiso en el trabajo implican un mayor bienestar, que incrementa la energía y motivación del colaborador para alcanzar sus metas personales y laborales (Mäkikangas, Hyvönen \& Feldt, 2017).

Además de ello, se encontró una relación positiva y significativa entre realización personal y apoyo directivo. Estos resultados coinciden con algunos estudios internacionales realizados en personal de salud, que encontraron que el mayor apoyo recibido de la institución se asocia con un mejor desempeño en sus labores (García et al., 2009; Jorge et al., 2005; Vega et al., 2017). A su vez, en el personal policial el mayor apoyo social (superiores y compañeros), la mayor promoción laboral (Acevedo, 2010), el empoderamiento psicológico y la retroalimentación del supervisor, disminuyen los niveles de burnout (Gong, Zhang, Zhao \& Yin, 2017), lo que interviene de manera positiva en el servicio prestado a la comunidad (Brunetto et al., 2017), promoviendo la manifestación de mayores niveles de realización personal (Mikkelsen \& Burke, 2004). Por lo cual, en el entorno nacional se observó que un clima laboral interviene significativamente en la realización personal del efectivo policial (García, 2016).Por consiguiente, es fundamental que los directivos promuevan la autonomía, las competencias profesionales y motiven a sus subordinados valorando el esfuerzo que los policías realizan al estar constantemente expuestos al peligro en el servicio prestado a la comunidad (Magny, 2012).

Por otro parte, con respecto a las variables sociodemográficas se encontró que la edad se relaciona de manera negativa y significativa con el distanciamiento emocional, la 
realización personal y la carga de trabajo, debido a que los efectivos policiales de mayor edad presentan menor agotamiento emocional por la menor presión que reciben por parte de sus superiores y por la delegación de funciones que realizan. Igualmente, en algunos estudios nacionales realizados por Cabanillas (2016) y Calienes y Díaz (2012), se observó que los suboficiales de mayor edad presentaron menor agotamiento emocional y despersonalización, mientras que los efectivos de menor edad mostraron un mayor agotamiento emocional. Esta situación podría ser explicada debido a que los efectivos policiales de mayor edad desempeñan funciones administrativas con menor exposición al riesgo, lo que determina un menor nivel de burnout; mientras que los efectivos más jóvenes muestran un mayor desgaste emocional, debido a que realizan funciones operativas de riesgo que los exponen a un mayor nivel de estrés. Por otro lado, Callirgos (2017) no encontró diferencias significativas entre la edad y el distanciamiento emocional (agotamiento emocional y la despersonalización) y la realización personal. Por otro parte, en la investigación de Ritter, Fernandes, Kirchner, Schmidt y Ubessi (2012), se encontró una relación directa entre el agotamiento emocional, la realización personal y la edad en el personal de salud. Cabe resaltar que de acuerdo a los hallazgos Aguayo et al. (2017) la edad no es un factor determinante que contribuya al desarrollo del burnout.

Con respecto a la variable sociodemográfica tiempo que lleva trabajando, se encontró una correlación negativa y significativa con la realización personal y carga de trabajo, mientras que con el distanciamiento emocional (despersonalización y realización personal) no presento una correlación significativa. De forma similar, Gonzales (2017) no encontró diferencias significativas entre el tiempo de servicio y el síndrome de burnout. Asimismo, Callirgos (2017), en su estudio no observó diferencias significativas entre el tiempo que lleva trabajando y el agotamiento emocional. Sin embargo, encontró diferencias significativas con la realización personal y la despersonalización. 
Por otra parte, no se encontraron resultados coherentes de las variables sociodemográficas: género, estado civil, número de hijos, grado policial y horas de jornada laboral con la teoría ni con los resultados encontrados en el análisis de correlación de las variables ya que, por ejemplo se observa que a mayor tiempo de jornada laboral (más horas de trabajo), se percibe un menor agotamiento emocional. Lo mencionado anteriormente, contradice el resultado observado en el análisis de correlación que indica que a mayor carga de trabajo (más demandas y horas de trabajo) se presenta mayor agotamiento emocional. De manera similar, el estudio de Cabanillas (2016), reportó que no existen diferencias entre distanciamiento emocional (agotamiento emocional y despersonalización) y realización personal con las variables sexo, estado civil y número de hijos. A su vez, Gonzales (2017) agrega que no existen diferencias significativas entre el grado y el síndrome de burnout. Adicionalmente, Aguayo et al. (2017) no es un factor que impacta en la aparición del burnout. 


\section{Conclusiones}

Por lo tanto, se concluye que existe relación entre el síndrome de burnout y la calidad de vida profesional en los efectivos policiales de Lima Metropolitana. Los resultados empíricos encontrados, confirman que es importante que la administración de la institución realice una adecuada gestión tanto en la asignación de las tareas asignadas; así como proporcione el apoyo directivo para fortalecer la motivación intrínseca en el personal policial y con ello prevenir el síndrome de burnout. Por ello, el análisis del síndrome burnout en la institución policial, es fundamental para desarrollar estrategias que prevengan los desórdenes originados por su aparición (Corredor \& Marín, 2013).

\section{Limitaciones y Recomendaciones}

Por otra parte, durante el desarrollo de la investigación se presentaron algunas limitaciones tales como: la escasez de estudios bibliográficos de análisis de la correlación entre las variables de estudio que aportaran mayor evidencia a los resultados encontrados; el tamaño reducido de la muestra, debido al muestro no probabilístico intencional utilizado que limita la generalización de los resultados encontrados a la población; el no haber tomado en cuenta dentro de los criterios sociodemográficos la especialidad de los evaluados que ayude a determinar cuáles son las posiciones más expuestas al burnout; el lenguaje de los ítems de los cuestionarios que afecta su compresión y dificulta su aplicación; y la cantidad elevada de ítems de los cuestionarios, que genera cansancio y desinterés en la conclusión de las pruebas.

Por ello, se recomienda desarrollar un mayor análisis de las variables de estudio para observar su comportamiento en diferentes poblaciones y comprender de qué manera el síndrome de burnout afecta la calidad de vida profesional, con la finalidad de informar a la comunidad la importancia de la interacción de ambos fenómenos y sus consecuencias en el profesional y la organización. Asimismo, se sugiere utilizar un muestro probabilístico 
representativo, que permita realizar inferencia de los resultados encontrados a la población de estudio, con lo cual se podría generalizar los resultados obtenidos a toda la población policial. Además, se recomienda incorporar el criterio de especialidad del policía para poder observar que tan determinante es este factor en la generación de estrés. También, se sugiere conformar un equipo multidisciplinario constituido por psicólogos y personal policial que aporte en la adaptación del lenguaje utilizado de los cuestionarios para que se pueda realizar una mejor aplicación. Adicionalmente, se recomienda diseñar versiones abreviadas de los cuestionarios con el objetivo de realizar la aplicación de una manera más dinámica, para minimizar el cansancio en el profesional y evitar alteraciones en los resultados.

De acuerdo a lo señalado, el estudio realizado contribuye a la línea de investigación de la psicología de la salud en el ámbito laboral; la cual se especializa en aplicar los principios y conocimientos científicos para elaborar diagnósticos, prevenir, explicar y tratar los trastornos físicos, psicológicos y conductuales que afectan los procesos de la salud (Oblitas como se citó en Oblitas, 2008). Por tal motivo, los hallazgos de la investigación sugieren garantizar el bienestar de los colaboradores en su práctica profesional y aportar conocimiento a las organizaciones, para resaltar la importancia del vínculo de los desórdenes psicológicos y conductuales propios del síndrome de burnout y el deterioro de la calidad de vida profesional del colaborador. Finalmente, la evidencia encontrada destaca la prevención del síndrome de burnout para promover la calidad de vida de los colaboradores y fortalecer su desempeño en la organización. 


\section{Referencias}

Acevedo, R. (2010). Síndrome de Burnout en cuerpos de Policía. Estado del arte (Tesis de maestría, Universidad de Barcelona, Barcelona, España). Recuperado de http://babel.banrepcultural.org/cdm/ref/collection/p17054coll23/id/56

Aguayo, R., Vargas, C., Cañadas, G. \& De la Fuente, E. (2017). Are Socio-Demographic Factors Associated to Burnout Syndrome in Police Officers A Correlational MetaAnalysis. Anales de Psicología, 33(2), 383-392. doi:

http://dx.doi.org/10.6018/analesps.33.2.260391

Alonso, M., Iglesias, A. \& Franco, A. (2002). Percepción de la calidad de vida profesional en un área sanitaria de Asturias. Atención Primaria, 30(8), 483-489. Recuperado de www.elsevier.es/es-revista-atencion-primaria-27-pdf-13039527-S300

Álvarez, R., Sánchez, R. \& Lorenzo, M. (2006). Consideraciones sobre la calidad de vida profesional en los trabajadores de atención primaria de Madrid. Atención Primaria, 37(5), 305-306. doi: 10.1157/13086300

Arias, W. \& Jiménez, N. (2012). Estudio comparativo del síndrome de burnout en enfermeras, policías y docentes de Arequipa. Revista de psicología de Arequipa, 2(2), 180-206. Recuperado de https://www.researchgate.net/publication/275584033 ESTUDIO_COMPARATIVO DEL_SINDROME_DE_BURNOUT_EN_ENFERMERAS_POLICIAS_Y_DOCENT ES DE AREQUIPA 
Arriola, O., Bocanegra, C. \& Sim, M. (2017). El proceso de reclutamiento y selección en la Escuela de Oficiales de la Policía Nacional del Perú (Tesis de Maestría, Universidad Del Pacifico). Recuperado de http://repositorio.up.edu.pe/bitstream/handle/11354/1937/Oscar Tesis maestria 2017 . pdf? sequence $=1 \&$ is Allowed $=y$

Basinska, B. \& Wiciak, I. (2012). Fatigue And Professional Burnout In Police Officers And Firefighters. Internal Security, 4(2), 265-273. Recuperado de $\underline{\text { http://internalsecurity.wspol.eu/ }}$

Basinska, B., Wiciak, I. \& Dåderman, A. (2014). Fatigue and burnout in police officers: the mediating role of emotions. Policing: An International Journal of Police Strategies \& Management, 37(3), 665-680. doi:http://dx.doi.org/10.1108/PIJPSM-10-2013-0105

Briones, D. (2007). Presencia de Síndrome de Burnout en Poblaciones Policiales Vulnerables de Carabineros de Chile. Ciencia \& Trabajo, 9(24), 43-50. Recuperado de www.cienciaytrabajo.cl/cytqa/EdicionesAnteriores/Volumen\%2024.pdf

Brunetto, Y., Farr-Wharton, B., Farr-Wharton, R., Shacklock, K., Azzopardi, J., Saccon, C. \& Shriberg, A. (2017). Comparing the impact of management support on police officers' perceptions of discretionary power and engagement: Australia, USA and Malta. The International Journal of Human Resource Management, 1-22. doi:http://dx.doi.org/10.1080/09585192.2017.1375964

Cabanillas, W. (2016). Síndrome de burnout según variables demográficas en policías del Departamento de Control de Tránsito Zona Lima Centro, 2016 (Tesis de Licenciatura, Universidad César Vallejo). Recuperado de http://repositorio.ucv.edu.pe/bitstream/handle/UCV/4066/Cabanillas_AWY.pdf?seque $\underline{\text { nce }=1 \& \text { isAllowed }=y}$ 
Cáceres, C. \& Tavera, M. (2013). Burnout y condiciones laborales en enfermeras y técnicas de cuidados intensivos neonatales (Tesis de licenciatura, Pontificia Universidad Católica del Perú). Recuperado de http://tesis.pucp.edu.pe/repositorio/handle/123456789/5099

Calienes, V. \& Díaz, F. (2012). Inteligencia emocional y síndrome de burnout en los SubOficiales de la Policía Nacional del Perú (Tesis de Licenciatura, Universidad Católica de Santa María). Recuperado de https://tesis.ucsm.edu.pe/repositorio/bitstream/handle/UCSM/3755/76.0197.PS.pdf?se quence $=1 \&$ is Allowed $=\mathrm{y}$

Callirgos, Y. (2017). Síndrome de burnout, según función en suboficiales de policía de las comisarías de Cercado de Lima, 2017 (Tesis de Licenciatura, Universidad César Vallejo). Recuperado de http://repositorio.ucv.edu.pe/bitstream/handle/UCV/11245/Callirgos_DYE.pdf?seque $\underline{\text { nce }=1 \& \text { isAllowed }=y}$

Cárdenas, M. \& Arancibia, H. (2014). Potencia Estadística y Cálculo del Tamaño del Efecto en G*Power: Complementos a las Pruebas de Significación Estadística y su Aplicación en Psicología. Revista Salud \& Sociedad, 5(2), 210-224. Recuperado de https://dialnet.unirioja.es/servlet/articulo?codigo $=4945415$

Cárdenas, S. (2013). Las aspiraciones laborales en un grupo de personas que estudian y trabajan en Lima (Tesis de licenciatura, Universidad Peruana de Ciencias Aplicadas). Recuperado de http://repositorioacademico.upc.edu.pe/upc/bitstream/10757/314812/2/cardenas pspub-tesis.pdf 
Castañeda, E. \& García, J. (2010). Prevalencia del síndrome de agotamiento profesional (burnout) en médicos familiares mexicanos: análisis de factores de riesgo. Revista Colombiana de Psiquiatría, 39 (1), 67-84. Recuperado de http://www.redalyc.org/pdf/806/80615449006.pdf

Castillo, F. (2015). Deficiencias en el procedimiento de convocatoria, selección y evaluación de los docentes en la Escuela de Oficiales de la Policía Nacional del Perú durante el periodo 2010 -2013 (Tesis de licenciatura, Pontificia Universidad Católica del Perú). Recuperado de http://tesis.pucp.edu.pe/repositorio/bitstream/handle/123456789/6500/CASTILLO_L UQUE_FREDY_EDUARDO_DEFICIENCIAS.pdf?sequence=1

Contreras, F., Espinosa, J., Hernández, F. \& Acosta, N. (2013). Calidad de vida laboral y liderazgo en trabajadores asistenciales y administrativos en un centro oncológico de Bogotá (Colombia). Psicología desde el Caribe, 30(3), 569-590. Recuperado de http://www.redalyc.org/pdf/213/21329176007.pdf

Corredor, N. \& Marín, L. (2013). Burnout en miembros de la policía nacional de Colombia: un análisis crítico. Revista de investigaciones de la escuela de administración y mercadotecnia del Quindío, 5(5), 62-73. Recuperado de https://dialnet.unirioja.es/servlet/articulo;jsessionid=B36326129E9CDCB1E204943C 1DAAB574.dialnet $02 ?$ codigo $=4955436$

Durán, M. (2010). Bienestar psicológico: El estrés y la calidad de vida en el contexto laboral. Revista nacional de administración, 1(1) ,71-84. Recuperado de https://dialnet.unirioja.es/descarga/articulo/3698512.pdf 
Durán, M. \& Montalbán, M. (2000). El estrés laboral en el ámbito policial. (ESPAM Boletín Informativo 2-2000). Recuperado de http://espam.malaga.eu/catalogo/BOLETINES/ARTICULOS/ARTICULO02.PDF

Easton, S., Van Laar, D. \& Marlow-Vardy, R. (2013). Quality of Working Life and the Police. Journal of Management, 3(3), 135-141. doi:10.5923/j.mm.20130303.01

Euwema, M., Kop, N. \& Bakker, A. (2004). The behaviour of police officers in conflict situations: How burnout and reduced dominance contribute to better outcomes. Work \& Stress, 18(1), 23-28. doi:10.1080/0267837042000209767

Faleiros, F. (2008). Hardiness (personalidade resistente): Repercussões na qualidade de vida profissional em colaboradores de uma cooperativa de crédito do estado de Mato Grosso do Sul (Tesis de maestría, Universidad Católica Dom Bosco, Campo Grande, Brasil). Recuperado de http://site.ucdb.br/public/md-dissertacoes/8019-hardiness-personalidade-resistente$\underline{\text { repercussoes-na-qualidade-de-vida-profissional-em-colaboradores-de-uma- }}$ cooperativa-de-credito-do-estado-de-mato-grosso-do-sul.pdf

Ferrando, P. \& Anguiano-Carrasco, C. (2010). El análisis factorial como técnica de investigación en psicología. Papeles del Psicólogo, 31(1), 18-33. Recuperado de http://www.papelesdelpsicologo.es/pdf/1793.pdf

Gantiva, C., Tabares, S. \& Villa, M. (2010). Síndrome de burnout y estrategias de afrontamiento en docentes de primaria y bachillerato. Psicología desde el Caribe, (26), 36-50. Recuperado de http://www.scielo.org.co/pdf/psdc/n26/n26a03.pdf 
García, A. (2016). Clima laboral y Síndrome de Burnout en trabajadores de la Policía Nacional del Perú, 2016 (Tesis de Licenciatura, Universidad César Vallejo). Recuperado de http://repositorio.ucv.edu.pe/bitstream/handle/UCV/1160/Garc\%C3\%ADa HAM.pdf ?sequence $=1 \&$ isAllowed $=\mathrm{y}$

García, I., Gálvez, M. \& Rodríguez, A. (2009). Calidad de Vida Profesional y Burnout en Técnicos de Drogodependencia: Análisis Comparativo con otros Grupos Profesionales. Revista Medicina y Seguridad del Trabajo, 55(217), 12-26. doi: 10.4321/S0465-546X2009000400002

García, O. (2015). Factores que influyen en la definición del perfil profesional del egresado de la ETS-PNP y el desempeño laboral (Tesis de Licenciatura, Pontificia Universidad Católica Del Perú). Recuperado de http://tesis.pucp.edu.pe/repositorio/bitstream/handle/123456789/6710/GARCIA_CAS AS_OSWALDO_GERMAN_FACTORES.pdf? sequence $=1 \&$ isAllowed $=\mathrm{y}$

Gong, Z. \& Zhang, J. (2015). Job Burnout and Psychological Empowerment among Police in Mainland China. Iranian Journal of Public Health, 44(7), 1014-1015. Recuperado de https://www.ncbi.nlm.nih.gov/pmc/articles/PMC4645751/pdf/IJPH-44-1014.pdf

Gong, Z., Zhang, J., Zhao, Y. \& Yin, L. (2017). The relationship between feedback environment, feedback orientation, psychological empowerment and burnout among police in China. Policing: An International Journal of Police Strategies \& Management, 40(2), 336-350. doi: https://doi.org/10.1108/PIJPSM-03-2016-0046 
Gonzales, A. (2017). Síndrome de burnout y agresividad en los efectivos de la Policía Nacional del Perú de las comisarias del distrito de Comas, Lima 2017 (Tesis de Licenciatura, Universidad César Vallejo). Recuperado de http://repositorio.ucv.edu.pe/bitstream/handle/UCV/3267/Gonzales FAY.pdf?sequen $\underline{\text { ce }=1 \& \text { isAllowed }=y}$

Gonzáles, M. \& Sandoval, M. (2016). Calidad de vida profesional y síndrome de Burnout en enfermeras del hospital María Auxiliadora. Revista de Ciencia y Arte de Enfermería, 2(1) ,15-21. doi: http://dx.doi.org/10.24314/race.v1i2.28

Grajales, T. (2000). Estudio de la validez factorial del Maslach Burnout Inventory versión Española en una población de profesionales mexicanos. Recuperado de http://tgrajales.net/mbivalidez.pdf

Grimaldo, M. (2010). Calidad de Vida Profesional en Estudiantes de Ciencias de la Salud. Revista de psicología, (12), 51-80. Recuperado de http://sisbib.unmsm.edu.pe/BVRevistas/rev_psicologia_cv/v12_2010/pdf/a03.pdf

Grimaldo, M. \& Reyes, M. (2014). Calidad de vida profesional y sueño en profesionales de Lima. Revista latinoamericana de psicología, 47(1), 50-57. Recuperado de http://www.redalyc.org/pdf/805/80535395006.pdf

Hernández, R., Fernández, C. \& Baptista, P. (2014). Metodología de la investigación. (6a ed.). México: McGraw-Hill.

Hogarth, M. (2017). Avoiding Burnout. En S. Schmehl \& M. Matteson (Eds. de la serie), Emotion in the Library Workplace: Vol. 37. Advances in Library Administration and Organization (pp. 71-98). doi:https://doi.org/10.1108/S0732-067120170000037005 
Jorge, F., Blanco, M., Issa, S., Romero, L. \& Gayoso, P. (2005). Relación de la calidad de vida profesional y el burnout en médicos de atención primaria. Atención Primaria, 36(8), 442-447. doi:10.1157/13081058

Ley de la Policía Nacional del Perú Decreto Legislativo Nº1148 (2012). E1 Peruano. En: Lima. Recuperado de http://www.peru.gob.pe/docs/PLANES/13185/PLAN_13185_2016_DL.1148LEY PNP.PDF

Ley de la Policía Nacional del Perú Decreto Legislativo N¹318 (2018). El Peruano. En: Lima. Recuperado de https://busquedas.elperuano.pe/download/url/decreto$\underline{\text { legislativo-que-regula-la-formacion-profesional-de-1-decreto-legislativo-n-1318- }}$ $\underline{1469782-1}$

Ley de la Policía Nacional del Perú Decreto Supremo N026-2017-IN. (2017). El Peruano. En: Lima. Recuperado de https://elperuano.pe/NormasElperuano/2017/10/15/1576324-1/1576324-1.htm

Ley de la Policía Nacional del Perú Resolución Directoral N²00-2018-DIRGEN/IG-PNP. (2018). Recuperado de https://www.policia.gob.pe/resoluciones_directivas/RD\%20N\%C2\%B0200-2018DIRGEN-IG-

PNP\%20DEL\%2002JUN18\%20Y\%20DIRECTIVA\%20N\%C2\%B0\%2018-10-2018DIRGEN-PNP-DIRSAPOL-B.pdf 
Linares, A. \& Poma, Z. (2016). Estilos de afrontamiento al estrés y síndrome de burnout en una dependencia de la Policía Nacional del Perú de Lima, 2016 (Tesis de Licenciatura, Universidad Peruana Unión). Recuperado de http://repositorio.upeu.edu.pe/bitstream/handle/UPEU/430/Angie Tesis bachiller 20 16.pdf? sequence $=1 \&$ is Allowed $=\mathrm{y}$

López, A., López, J., Jareño, P. \& Moya, M. (2008). Influencia de los modelos de gestión en la calidad de vida profesional del personal cuidador en residencias de mayores de Albacete. Enfermería Clínica, 19(5), 258-266. doi:10.1016/j.enfcli.2009.04.005

López, B., Osca, A. \& Rodríguez, M. (2008). Estrés de rol, implicación con el trabajo y burnout en soldados profesionales españoles. Revista Latinoamericana de Psicología, 40(2), 293-304. Recuperado de http://www.redalyc.org/pdf/805/80500207.pdf

López, M., García, S. \& Pando, M. (2014). Factores de Riesgo Psicosocial y Burnout en Población Económicamente Activa de Lima, Perú. Ciencia \& Trabajo, (51), 164-169. doi: $10.4067 / \mathrm{S} 0718-24492014000300007$

Macías, A., Gutiérrez, C., Carmona, F. \& Crespillo, D. (2014). Relación de la inteligencia emocional y la calidad de vida profesional con la consecución de objetivos laborales en el distrito de atención primaria Costa del Sol. Atención Primaria, 48(5), 301-307. doi:10.1016/j.aprim.2015.06.007

Magny, O. (2012). Intrinsic And Extrinsic Factors That Influence Job Satisfaction in Police Officers Relative to Frederick Herzberg's Motivation/Hygiene Theory (Tesis de doctorado, University of La Verne, La Verne, California). Recuperado de https://media.proquest.com/media/pq/classic/doc/2889604661/fmt/ai/rep/NPDF?_s=1 WoLM66sKMdLXCGZtCyiSOndSi4\%3D 
Mäkikangas, A., Hyvönen, K. \& Feldt, T. (2017). The energy and identification continua of burnout and work engagement: Developmental profiles over eight year. Burnout Research, 5(2017), 44-54. doi:http://dx.doi.org/doi:10.1016/j.burn.2017.04.002

Maslach, C. (2009). Comprendiendo el burnout. Ciencia \& Trabajo, 11(32), 37-43.

Recuperado de

http://www.vitoriagasteiz.org/wb021/http/contenidosEstaticos/adjuntos/es/16/40/5164 $\underline{0 . p d f}$

Maslach, C. (2015). Burnout, Psychology of. International Encyclopedia of the Social \& Behavioral Sciences, $2^{\text {nd }}$ edition, 2, 929-932.doi: http://dx.doi.org/10.1016/B978-008-097086-8.26009-1

Maslach, C. \& Leiter, M. (2016a). Burnout. En G. Fink (Ed. de la serie), Handbook of Stress Series: Vol. 1. Stress: Concepts, Cognition, Emotion, and Behavior (pp. 351-357).doi: http://dx.doi.org/10.1016/B978-0-12-800951-2.00044-3

Maslach, C. \& Leiter, M. (2016b). Understanding the burnout experience: recent research and its implications for psychiatry. World Psychiatry, 2016(15), 103101.doi:10.1002/wps.20311

Maslach, C., Schaufeli, W. \& Leiter, M. (2001). Job Burnout. Annual Review of Psychology, (52), 397-422. Recuperado de http://www.wilmarschaufeli.nl/publications/Schaufeli/154.pdf

McCarty, W. \& Skogan, W. (2012). Job-Related Burnout Among Civilian and Sworn Police Personnel. Police Quarterly, 20(10), 1-19. Recuperado de http://skogan.org/files/Job_Burnout_Sworn_Civilians.Platform.PQ_2012.pdf 
Mikkelsen, A. \& Burke, R. (2004). Work-Family Concerns of Norwegian Police Officers: Antecedents and Consequences. International Journal of Stress Management, 11(4), 429-444. doi:10.1037/1072-5245.11.4.429

Muñoz, E., Coll, J., Torrent, M. \& Linares, L. (2004). Influencia del clima laboral en la satisfacción de los profesionales sanitarios. Atención primaria, 37(4), 209-214. Recuperado de

http://ac.els-cdn.com/S0212656706703341/1-s2.0-S0212656706703341main.pdf? tid=35d7926c-32b5-11e7-84d0$\underline{\text { 00000aab0f01\&acdnat }=1494114133 \quad 51 \mathrm{~d} 56956910967 \mathrm{~b} 356 \mathrm{c} 15 \mathrm{f} 12 \mathrm{ac} 9 \mathrm{~b} 6 \mathrm{e} 87}$

Oblitas, L. (2008). Psicología De La Salud: Una ciencia del bienestar y la felicidad. Avances en psicología, 16(1), 9-38. Recuperado de http://www.unife.edu.pe/pub/revpsicologia/psicologiasalud.pdf

Patlán, J. (2013). Efecto del burnout y la sobrecarga en la calidad de vida en el trabajo. Revista Estudios Gerenciales, 29(129), 445-455. Recuperado de http://ac.els-cdn.com/S0123592314000813/1-s2.0-S0123592314000813ain.pdf? tid=bdc8b240-126e-11e6-a50b-

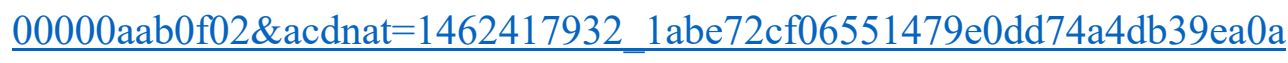

Prashant, D. (2014). Quality of Work Life of Police Constables with special reference to Wellness. IOSR Journal of Business and Management, 16(11), 46-51. Recuperado de http://iosrjournals.org/iosr-jbm/papers/Vol16-issue11/Version-4/G0161144651.pdf 
Puello, Y., Quintero, N., Canova, C., Camargo, Y., Amaya, L., Guzmán, Y. \& Cervantes, S. (2014). Calidad de vida percibida por el personal de enfermería de las unidades de cuidados intensivos de una clínica privada de la ciudad de Santa Marta. Investigación en Enfermería: Imagen y Desarrollo, 16(1), 87-99. Recuperado de http://www.redalyc.org/pdf/1452/145231426007.pdf

Ritter, R., Fernandes, E., Kirchner, R., Schmidt, C. \& Ubessi, L. (2012). Correlaciones de variables del Inventario de Burnout de Maslach en profesionales de urgencia hospitalaria. Enfermería Global, 11(3), 210-223. Recuperado de http://revistas.um.es/eglobal/article/view/155161

Rivera, D., Rivera, J. \& González, C. (2016). Validación de los cuestionarios CVP-35 y MBIHSS para calidad de vida profesional y burnout en residentes. Investigación en Educación Médica, 6(21), 25-34. Recuperado de http://ac.els-cdn.com/S2007505716300345/1-s2.0-S2007505716300345main.pdf? tid=6990a522-32b9-11e7-83c1$\underline{\text { 00000aab0f02\&acdnat }=1494115937 \quad 59495 \text { eabe3ab76b131df724fff1bcafa }}$

Rodríguez, S. \& Chávez, S. (2018).Calidad de Vida Profesional y el Síndrome de Burnout en el Personal de Enfermería que labora, en la Clínica Privada Jesús del Norte, Lima 2018 (Tesis de Licenciatura, Universidad Norbert Wiener). Recuperado de http://repositorio.uwiener.edu.pe/bitstream/handle/123456789/1870/TITULO\%20\%20Rodriguez $\% 20$ Sevillano $\% 2 \mathrm{c} \% 20 \% 20$ Leonor.pdf? sequence $=1 \&$ is Allowed $=\mathrm{y}$

Romero, A. (2015). Burnout y cólera en policías de una unidad de emergencia de lima (Tesis de licenciatura, Pontificia Universidad Católica del Perú). Recuperado de http://tesis.pucp.edu.pe/repositorio/handle/123456789/6394 
Sánchez, R., Álvarez, R. \& Lorenzo, S. (2003). Calidad de vida profesional de los trabajadores de Atención Primaria del Área 10 de Madrid. Revista de Medicina Familiar y Comunitaria, 13(4), 291-296. Recuperado de http://scielo.isciii.es/pdf/medif/v13n4/original5.pdf

Sánchez, J., Sanz, M., Apellániz, A. \& Pascual, A. (2001). Policía y estrés laboral. Estresores organizativos como causa de morbilidad psiquiátrica. Revista SESLAP, 1(4), 21-25. Recuperado de http://www.seslap.com/seslap/html/pubBiblio/revista/n_4/polestres.pdf

Schaufeli, W. (2017). Applying the Job Demands -Resources model: A 'how to' guide to measuring and tackling work engagement and burnout. Organizational Dynamics, 46(2), 120-132. doi: http://dx.doi.org/10.1016/j.orgdyn.2017.04.008

Schaible, L. \& Six, M. (2016). Emotional Strategies of Police and Their Varying Consequences for Burnout. Police Quarterly, 19(1), 3-31. doi:10.1177/109861115604448

Somoray, K.,Shakespeare-Finch, J. \& Armstrong, D. (2017). The Impact of Personality and Workplace Belongingness on Mental Health Workers' Professional Queality of Life. Australian Psychologist, 52(1), 52-60.doi:10.1111/ap.12182

Suasnabar, M. (2017). Síndrome de Burnout y calidad de vida profesional en Enfermería en un Instituto de Enfermedades Neurológicas. Lima, 2017 (Tesis de Maestría, Universidad César Vallejo). Recuperado de http://repositorio.ucv.edu.pe/bitstream/handle/UCV/14466/Suasnabar_CMK.pdf?sequ $\underline{\text { ence }}=1 \&$ is Allowed $=y$ 
Tapia, V. \& Luna, J. (2010). Validación de una prueba de habilidades de pensamiento para alumnos de cuarto y quinto de secundaria y primer año de universidad. Revista de Investigación en Psicología, 13(2), 17-59. Recuperado de http://revistasinvestigacion.unmsm.edu.pe/index.php/psico/article/view/3710/2974

Toledo, E. (2016). Prevalencia del síndrome de burnout en el personal de salud de la Clínica Maison de Sante de Lima (Tesis de Licenciatura, Universidad Nacional Mayor de San Marcos). Recuperado de http://cybertesis.unmsm.edu.pe/bitstream/cybertesis/4649/1/Toledo_ne.pdf

Tomás-Sábado, J. (2011). Estructura factorial de la Escala de Vida Profesional (CVP-35) en enfermeras de Atención Primaria. Revista Psicología.com, 15(23), 1-7. Recuperado de https://www.researchgate.net/publication/262727298_Estructura_factorial_de_la_Esc ala de Calidad de Vida Profesional CVP 35 en enfermeras de Atencion Primaria

Valladares, I. (2017). Síndrome de burnout en agentes policiales de la División Policial de Huaral Perú 2017 (Tesis de Licenciatura, Universidad César Vallejo). Recuperado de http://repositorio.ucv.edu.pe/bitstream/handle/UCV/6193/Valladares LI.pdf?sequence $\underline{=1}$

Vega, E., Gómez, J., Caballero, I. \& Contreras, F. (2017). Síndrome de burnout y calidad de vida laboral en personal asistencial de una institución de salud en Bogotá. Informes Psicológicos, 17(1), 87-105. Recuperado de http://dx.doi.org/10.18566/infpsic.v17n1a05 
Villarín, A., Méndez, T., Zuzúarregui, M., Sánchez, S. \& Conejo, R. (2015). Calidad de vida profesional en trabajadores del área de atención primaria de Toledo. Revista De Calidad Asistencial, 30(1), 4-9. Recuperado de https://dialnet.unirioja.es/servlet/articulo? codigo=4996952

Vizcarra, M., Llaja, V., Limo, C. \& Talavera, J. (2015). Clima laboral, Burnout y Perfil de Personalidad: Un estudio en personal asistencial de un Hospital Público de Lima. Informes Psicológicos, 15(2), 111-126. Recuperado de https://dialnet.unirioja.es/descarga/articulo/5293835.pdf

Vuorensyrjä, M. \& Mälkiä, M. (2011). Nonlinearity of the effects of police stressors on police officer burnout. Policing: An International Journal of Police Strategies \& Management, 34(3), 382-402. doi:http://dx.doi.org/10.1108/13639511111157474

Xavier, P. \& Prabhakar, K. (2016). A Study of Police Stress and Burnout among Tamil Nadu Police. International Journal of Pharmaceutical Sciences Review and Research, 38(2), 159-161. Recuperado de

globalresearchonline.net/journalcontents/v38-2/30.pdf

Zárate, J. (2017). Burnout y satisfacción laboral en el Personal de la División de Operaciones Especiales de la Región Policial Callao 2016 (Tesis de Maestría, Universidad César Vallejo). Recuperado de http://repositorio.ucv.edu.pe/bitstream/handle/UCV/7500/Z\%C3\%A1rate_JJF.pdf?seq $\underline{\text { uence }}=1 \&$ isAllowed $=y$ 


\section{Apéndices}

\section{Apéndice A}

\section{Consentimiento Informado}

La presente investigación conducida por la alumna Ana Lucia Zuazo Uribe, tiene como finalidad conocer la relación entre las variables síndrome de burnout y calidad de vida profesional en un grupo de Policías pertenecientes a la Policía Nacional del Perú de la ciudad de Lima. Su participación consiste en completar unas escalas de manera voluntaria. Usted podrá decidir la suspensión o cancelación de aplicación de las escalas, incluso después de iniciadas las mismas, si así lo considera pertinente.

El tiempo que demanda la aplicación de ambas escalas es aproximadamente de 30 minutos.

Los resultados no afectaran de forma alguna la integridad del participante. El alumno se compromete a respetar todas las normas éticas durante la aplicación de los instrumentos, asegurando así que la identidad del participante se mantenga en anonimato. Los resultados de los instrumentos serán utilizados con fines de aprendizaje, con el único objetivo anteriormente mencionado, manteniendo siempre la absoluta confidencialidad del participante. El (la) alumno (a), no podrá brindar ningún tipo de resultado o recomendación al participante, por tratarse de un proceso de aprendizaje y de formación.

Se tiene alguna duda podrá comunicarse al correo: analuciazuazou@gmail.com Yo identificado con DNI, acepto de manera voluntaria participar en un proceso de aplicación de instrumentos que será realizado por la alumna Ana Lucia Zuazo Uribe identificada con DNI 73310128 de la carrera de psicología ( Facultad de ciencias humanas) de la Universidad Peruana de Ciencias Aplicadas ( UPC). La evaluación se realizará como parte del proyecto de investigación.

Lima de 2016

Firma del participante

Firma del alumno 


\section{Apéndice B}

Ficha Sociodemográfica

\begin{tabular}{|l|}
\hline EDAD \\
\hline GÉNERO \\
$(\quad \quad$ MASCULINO \\
ESTADO CIVIL \\
NÚMERO DE HIJOS \\
GRADO POLICIAL \\
\hline DIAS DE TRABAJO SEMANANAL \\
\hline HORAS DE JORNADA EN LOS DIAS DE TRABAJO(SERVICIO) \\
\hline TIEMPO QUE LLEVA TRABAJANDO...HORAS EN LA INSTITUCIÓN \\
\hline
\end{tabular}




\section{Apéndice C}

Cuestionario 1: Inventario de Burnout de Maslach (Maslach \& Jackson, 1981)

Adaptado por Cárdenas (2013)

A continuación se presenta un conjunto de enunciados sobre diferentes ideas, pensamientos y situaciones relacionadas con su trabajo, usted debe contestar todos los ítems indicando la frecuencia con que se presentan. Debe marcar con un aspa $(\mathrm{X})$ sobre el recuadro que le corresponda, según la siguiente escala:

\begin{tabular}{|l|l|l|l|l|l|l|}
\hline Nunca & $\begin{array}{l}\text { Alguna } \\
\text { vez al año } \\
\text { o menos }\end{array}$ & $\begin{array}{l}\text { Una vez al } \\
\text { mes o } \\
\text { menos }\end{array}$ & $\begin{array}{l}\text { Algunas } \\
\text { veces al } \\
\text { mes }\end{array}$ & $\begin{array}{l}\text { Una vez } \\
\text { por } \\
\text { semana }\end{array}$ & $\begin{array}{l}\text { Algunas } \\
\text { veces por } \\
\text { semana }\end{array}$ & $\begin{array}{l}\text { Todos los } \\
\text { días }\end{array}$ \\
\hline$(0)$ & $(1)$ & $(2)$ & $(3)$ & $(4)$ & $(5)$ & $(6)$ \\
\hline
\end{tabular}

\begin{tabular}{|l|l|l|l|l|l|l|l|}
\hline \multicolumn{1}{|c|}{ Ítems } & Nunca & $\begin{array}{c}\text { Alguna } \\
\text { vez al } \\
\text { año o } \\
\text { menos }\end{array}$ & $\begin{array}{c}\text { Una } \\
\text { vez al } \\
\text { mes o } \\
\text { menos }\end{array}$ & $\begin{array}{c}\text { Algunas } \\
\text { veces al } \\
\text { mes }\end{array}$ & $\begin{array}{c}\text { Una } \\
\text { vez por } \\
\text { semana }\end{array}$ & $\begin{array}{c}\text { Algunas } \\
\text { veces } \\
\text { por } \\
\text { semana }\end{array}$ & $\begin{array}{c}\text { Todos } \\
\text { los } \\
\text { días }\end{array}$ \\
\hline $\begin{array}{l}\text { 1. Debido a mi trabajo me } \\
\text { siento emocionalmente } \\
\text { agotado }\end{array}$ & & & & & & \\
\hline $\begin{array}{l}\text { 2. Al final de la jornada me } \\
\text { siento agotado. }\end{array}$ & & & & & & & \\
\hline $\begin{array}{l}\text { 3. Me encuentro cansado } \\
\text { cuando me levanto por las } \\
\text { mañanas y tengo que } \\
\text { enfrentarme a otro día de } \\
\text { trabajo. }\end{array}$ & & & & & & & \\
\hline $\begin{array}{l}\text { 4. Puedo entender con } \\
\text { facilidad lo que piensan las } \\
\text { personas. }\end{array}$ & & & & & & & \\
\hline $\begin{array}{l}\text { 5. Creo que trato a algunas } \\
\text { personas con indiferencia. }\end{array}$ & & & & & & & \\
\hline $\begin{array}{l}\text { 6. Trabajar con personas } \\
\text { todos los días es una tensión } \\
\text { para mí. }\end{array}$ & & & & & & & \\
\hline $\begin{array}{l}\text { 7. Me enfrento muy bien a } \\
\text { los problemas que me } \\
\text { presentan los demás. }\end{array}$ & & & & & & & \\
\hline $\begin{array}{l}\text { 8. Me siento agotado por el } \\
\text { trabajo. }\end{array}$ & & & & & & & \\
\hline
\end{tabular}




\begin{tabular}{|c|c|c|c|c|c|c|c|}
\hline Ítems & $\begin{array}{c}\text { Nun } \\
\text { ca }\end{array}$ & \begin{tabular}{|l|} 
Alguna \\
vez al \\
año o \\
menos \\
\end{tabular} & \begin{tabular}{|c|} 
Una \\
vez al \\
mes o \\
menos \\
\end{tabular} & $\begin{array}{c}\text { Algunas } \\
\text { veces al } \\
\text { mes }\end{array}$ & $\begin{array}{c}\text { Una } \\
\text { vez por } \\
\text { semana }\end{array}$ & $\begin{array}{l}\text { Algunas } \\
\text { veces } \\
\text { por } \\
\text { semana } \\
\end{array}$ & $\begin{array}{l}\text { Todos } \\
\text { los días }\end{array}$ \\
\hline \multicolumn{8}{|l|}{$\begin{array}{l}\text { 9. Siento que mediante mi } \\
\text { trabajo estoy influyendo } \\
\text { positivamente en la vida de } \\
\text { otros. }\end{array}$} \\
\hline \multicolumn{8}{|l|}{$\begin{array}{l}\text { 10. Creo que me comporto de } \\
\text { manera más insensible con la } \\
\text { gente desde que hago este } \\
\text { trabajo. }\end{array}$} \\
\hline \multicolumn{8}{|l|}{$\begin{array}{l}\text { 11. Me preocupa que este } \\
\text { trabajo me esté endureciendo } \\
\text { emocionalmente. }\end{array}$} \\
\hline \multicolumn{8}{|l|}{$\begin{array}{l}\text { 12. Me encuentro con mucha } \\
\text { vitalidad. }\end{array}$} \\
\hline \multicolumn{8}{|l|}{$\begin{array}{l}\text { 13. Me siento frustrado por } \\
\text { mi trabajo. }\end{array}$} \\
\hline \multicolumn{8}{|l|}{$\begin{array}{l}\text { 14. Siento que estoy haciendo } \\
\text { un trabajo demasiado duro. }\end{array}$} \\
\hline \multicolumn{8}{|l|}{$\begin{array}{l}\text { 15. Trato de mantenerme al } \\
\text { margen de los problemas } \\
\text { personales de los demás. }\end{array}$} \\
\hline \multicolumn{8}{|l|}{$\begin{array}{l}\text { 16. Trabajar en contacto } \\
\text { directo con las personas me } \\
\text { produce bastante estrés. }\end{array}$} \\
\hline \multicolumn{8}{|l|}{$\begin{array}{l}\text { 17. Tengo facilidad para crear } \\
\text { un ambiente relajado para los } \\
\text { demás. }\end{array}$} \\
\hline \multicolumn{8}{|l|}{$\begin{array}{l}\text { 18. Me encuentro animado } \\
\text { después de trabajar junto con } \\
\text { mis clientes. }\end{array}$} \\
\hline \multicolumn{8}{|l|}{$\begin{array}{l}\text { 19. He realizado muchas } \\
\text { cosas que valen la pena en } \\
\text { este trabajo. }\end{array}$} \\
\hline \multicolumn{8}{|l|}{$\begin{array}{l}\text { 20. En el trabajo siento que } \\
\text { he llegado al límite de mis } \\
\text { posibilidades. }\end{array}$} \\
\hline \multicolumn{8}{|l|}{$\begin{array}{l}\text { 21. Siento que se trata de } \\
\text { forma adecuada los conflictos } \\
\text { emocionales en el trabajo. }\end{array}$} \\
\hline $\begin{array}{l}\text { 22. En mi trabajo, me } \\
\text { incomoda que las personas } \\
\text { me interrumpan por sus } \\
\text { problemas personales, por los } \\
\text { cuales no me interesa ser } \\
\text { molestado. }\end{array}$ & & & & & & & \\
\hline CONTINUE & $20 \mathrm{~N}$ & EL SIC & IENTI & CUESTI & IONARI & & \\
\hline
\end{tabular}




\section{Apéndice D}

\section{Cuestionario 2: Escala De Calidad De Vida Profesional (Cvp - 35) (Cabezas, 1998)}

Adaptado por Grimaldo y Reyes (2014)

A continuación le presentaremos una serie de frases acerca de situaciones relacionadas con su trabajo, Piense en su situación laboral, deberá responder dentro de una escala del 1 al 10, donde 1 es nada y 10 es mucho. Debe marcar con un aspa $(\mathrm{X})$ sobre el recuadro del número que le corresponda, según la siguiente escala:

\begin{tabular}{|c|c|c|c|c|c|c|c|c|c|c|}
\hline \multirow{2}{*}{ Ítems } & \multicolumn{2}{|c|}{ NADA } & \multicolumn{3}{|c|}{ ALGO } & \multicolumn{3}{|c|}{ BASTANTE } & \multicolumn{2}{|c|}{ MUCHO } \\
\hline & 1 & 2 & 3 & 4 & 5 & 6 & 7 & 8 & 9 & 10 \\
\hline 1. Cantidad de trabajo que tengo & & & & & & & & & & \\
\hline $\begin{array}{l}\text { 2. Prisas y agobios por la falta de } \\
\text { tiempo para realizar mi trabajo }\end{array}$ & & & & & & & & & & \\
\hline $\begin{array}{l}\text { 3. Presión que recibo para realizar } \\
\text { la cantidad de trabajo que tengo }\end{array}$ & & & & & & & & & & \\
\hline $\begin{array}{l}\text { 4. Presión que recibo para } \\
\text { mantener la calidad de mi trabajo }\end{array}$ & & & & & & & & & & \\
\hline $\begin{array}{l}\text { 5. Los conflictos que tengo con } \\
\text { otras personas de mi trabajo }\end{array}$ & & & & & & & & & & \\
\hline $\begin{array}{l}\text { 6. La falta de tiempo para mi vida } \\
\text { personal }\end{array}$ & & & & & & & & & & \\
\hline $\begin{array}{l}\text { 7. La incomodidad física en el } \\
\text { trabajo }\end{array}$ & & & & & & & & & & \\
\hline 8. La carga de responsabilidad & & & & & & & & & & \\
\hline 9. Las interrupciones molestas. & & & & & & & & & & \\
\hline $\begin{array}{l}\text { 10. El estrés que tengo (esfuerzo } \\
\text { emocional) }\end{array}$ & & & & & & & & & & \\
\hline $\begin{array}{l}\text { 11. Mi trabajo tiene consecuencias } \\
\text { negativas para mi salud }\end{array}$ & & & & & & & & & & \\
\hline $\begin{array}{l}\text { 12. Satisfacción con el tipo de } \\
\text { trabajo }\end{array}$ & & & & & & & & & & \\
\hline $\begin{array}{l}\text { 13. La motivación que } \\
\text { experimento (ganas de esforzarme) }\end{array}$ & & & & & & & & & & \\
\hline $\begin{array}{l}\text { 14. La exigencia de capacitación } \\
\text { para realizar mi trabajo }\end{array}$ & & & & & & & & & & \\
\hline 15. El apoyo de mi familia & & & & & & & & & & \\
\hline 16. Mis ganas de ser creativo(a) & & & & & & & & & & \\
\hline $\begin{array}{l}\text { 17. La capacitación que tengo para } \\
\text { hacer mi trabajo actual }\end{array}$ & & & & & & & & & & \\
\hline $\begin{array}{l}\text { 18. Mi trabajo es importante para } \\
\text { la vida de otras personas }\end{array}$ & & & & & & & & & & \\
\hline $\begin{array}{l}\text { 19. Me siento orgulloso(a) de mi } \\
\text { trabajo }\end{array}$ & & & & & & & & & & \\
\hline
\end{tabular}




\begin{tabular}{|c|c|c|c|c|c|c|c|c|c|c|}
\hline \multirow{2}{*}{ Ítems } & \multicolumn{2}{|c|}{ NADA } & \multicolumn{3}{|c|}{ ALGO } & \multicolumn{3}{|c|}{ BASTANTE } & \multicolumn{2}{|c|}{ MUCHO } \\
\hline & 1 & 2 & 3 & 4 & 5 & 6 & 7 & 8 & 9 & 10 \\
\hline $\begin{array}{l}\text { 20. Lo que tengo que hacer queda } \\
\text { claro }\end{array}$ & & & & & & & & & & \\
\hline $\begin{array}{l}\text { 21. El apoyo que recibo de mi } \\
\text { equipo }\end{array}$ & & & & & & & & & & \\
\hline $\begin{array}{l}\text { 22. Posibilidad de expresar lo que } \\
\text { siento y necesito }\end{array}$ & & & & & & & & & & \\
\hline 23. Satisfacción con el sueldo & & & & & & & & & & \\
\hline $\begin{array}{l}\text { 24. El reconocimiento de mi } \\
\text { esfuerzo }\end{array}$ & & & & & & & & & & \\
\hline $\begin{array}{l}\text { 25. La posibilidad de ser } \\
\text { promocionado(a) }\end{array}$ & & & & & & & & & & \\
\hline 26. El apoyo de mis jefes & & & & & & & & & & \\
\hline $\begin{array}{l}\text { 27. El apoyo de mis } \\
\text { compañeros(as) }\end{array}$ & & & & & & & & & & \\
\hline $\begin{array}{l}\text { 28. Recibo información de los } \\
\text { resultados de mi trabajo }\end{array}$ & & & & & & & & & & \\
\hline $\begin{array}{l}\text { 29. La institución donde trabajo } \\
\text { trata de mejorar la calidad de vida } \\
\text { de mi puesto }\end{array}$ & & & & & & & & & & \\
\hline $\begin{array}{l}\text { 30. Tengo autonomía o libertad de } \\
\text { decisión }\end{array}$ & & & & & & & & & & \\
\hline 31. La variedad en mi trabajo & & & & & & & & & & \\
\hline 32. La posibilidad de ser creativo & & & & & & & & & & \\
\hline $\begin{array}{l}\text { 33. La posibilidad de ser } \\
\text { escuchado(a), cuando realizo } \\
\text { alguna propuesta }\end{array}$ & & & & & & & & & & \\
\hline
\end{tabular}




\section{Apéndice E}

Solución factorial con tres dimensiones del MBI

Matriz de patrón ${ }^{\mathrm{a}}$

\begin{tabular}{|c|c|c|c|}
\hline \multirow{2}{*}{ Ítems } & \multicolumn{3}{|c|}{ Factor } \\
\hline & 1 & 2 & 3 \\
\hline 13. Me siento frustrado por mi trabajo. & 0.6 & & \\
\hline 12. Me encuentro con mucha vitalidad. & 0.59 & & \\
\hline $\begin{array}{l}\text { 14. Siento que estoy haciendo un trabajo } \\
\text { demasiado duro. }\end{array}$ & 0.57 & & \\
\hline $\begin{array}{l}\text { 16. Trabajar en contacto directo con las } \\
\text { personas me produce.... }\end{array}$ & 0.56 & & \\
\hline $\begin{array}{l}\text { 5. Creo que trato a algunas personas con } \\
\text { indiferencia. }\end{array}$ & 0.56 & & \\
\hline $\begin{array}{l}\text { 20. En el trabajo siento que he llegado al } \\
\text { límite de mis posibilidades. }\end{array}$ & 0.48 & & \\
\hline $\begin{array}{l}\text { 6. Trabajar con personas todos los días es } \\
\text { una tensión para mí. }\end{array}$ & 0.48 & & \\
\hline $\begin{array}{l}\text { 15. Trato de mantenerme al margen de los } \\
\text { problemas personales de los demás. }\end{array}$ & 0.44 & & \\
\hline $\begin{array}{l}\text { 11. Me preocupa que este trabajo me esté } \\
\text { endureciendo emocionalmente. }\end{array}$ & 0.38 & & \\
\hline $\begin{array}{l}\text { 21. Siento que se trata de forma adecuada } \\
\text { los conflictos emocionales en el trabajo. }\end{array}$ & & 0.59 & \\
\hline $\begin{array}{l}\text { 19. He realizado muchas cosas que valen la } \\
\text { pena en este trabajo. }\end{array}$ & & 0.57 & \\
\hline $\begin{array}{l}\text { 17. Tengo facilidad para crear un ambiente } \\
\text { relajado para los demás. }\end{array}$ & & 0.56 & \\
\hline 12. Me encuentro con mucha vitalidad. & & 0.52 & \\
\hline $\begin{array}{l}\text { 9. Siento que mediante mi trabajo estoy } \\
\text { influyendo positivamente... }\end{array}$ & & 0.46 & \\
\hline $\begin{array}{l}\text { 7. Me enfrento muy bien a los problemas } \\
\text { que me enfrentan los demás. }\end{array}$ & & 0.46 & \\
\hline $\begin{array}{l}\text { 18.Me encuentro animado después de } \\
\text { trabajar junto con mis clientes. }\end{array}$ & & 0.38 & \\
\hline $\begin{array}{l}\text { 1. Debido a mi trabajo me siento } \\
\text { emocionalmente agotado. }\end{array}$ & & & 0.77 \\
\hline 2. Al final de la jornada me siento agotado. & & & 0.69 \\
\hline 8. Me siento agotado por el trabajo. & & & 0.67 \\
\hline $\begin{array}{l}\text { 3. Me encuentro cansado cuando me levanto } \\
\text { por las mañanas y tengo que... }\end{array}$ & 0.31 & & 0.54 \\
\hline $\begin{array}{l}\text { 4.Puedo entender con facilidad lo que } \\
\text { piensan las personas. }\end{array}$ & & & 0.32 \\
\hline $\begin{array}{l}\text { 10. Creo que me comporto de manera más } \\
\text { insensible con .... }\end{array}$ & & & 0.3 \\
\hline
\end{tabular}

